\title{
Calibration of a distributed hydrology and land surface model using energy flux measurements
}

Larsen, Morten Andreas Dahl; Refsgaard, Jens Christian; Jensen, Karsten H.; Butts, Michael B.; Stisen, Simon; Mollerup, Mikkel

Published in:

Agricultural and Forest Meteorology

Link to article, DOI:

10.1016/j.agrformet.2015.11.012

Publication date:

2016

Document Version

Peer reviewed version

Link back to DTU Orbit

Citation (APA):

Larsen, M. A. D., Refsgaard, J. C., Jensen, K. H., Butts, M. B., Stisen, S., \& Mollerup, M. (2016). Calibration of a distributed hydrology and land surface model using energy flux measurements. Agricultural and Forest Meteorology, 217, 74-88. https://doi.org/10.1016/j.agrformet.2015.11.012

\section{General rights}

Copyright and moral rights for the publications made accessible in the public portal are retained by the authors and/or other copyright owners and it is a condition of accessing publications that users recognise and abide by the legal requirements associated with these rights.

- Users may download and print one copy of any publication from the public portal for the purpose of private study or research.

- You may not further distribute the material or use it for any profit-making activity or commercial gain

- You may freely distribute the URL identifying the publication in the public portal 
Agricultural and Forest Meteorology

Elsevier Editorial System(tm) for

Manuscript Draft

Manuscript Number: AGRFORMET-D-15-00325R1

Title: Calibration of a distributed hydrology and land surface model using energy flux measurements

Article Type: Research Paper

Section/Category: Energy Budget

Keywords: hydrology/land surface modelling; calibration; water and energy fluxes; evapotranspiration; energy closure imbalance

Corresponding Author: Dr. Morten Andreas Dahl Larsen, Ph.D.

Corresponding Author's Institution: Technical University of Denmark

First Author: Morten Andreas Dahl Larsen, Ph.D.

Order of Authors: Morten Andreas Dahl Larsen, Ph.D.; Jens C Refsgaard, Dr. Scient; Karsten H Jensen, Ph.D.; Michael B Butts, Ph.D.; Simon Stisen, Ph.D.; Mikkel Mollerup, Ph.D.

Abstract: In this study we develop and test a calibration approach on a spatially distributed groundwater-surface water catchment model (MIKE SHE) coupled to a land surface model component with particular focus on the water and energy fluxes. The model is calibrated against time series of eddy flux measurements from three sites of different land surface type (agriculture, forest and meadow) and river discharge data from the 2500 km2 Skjern River catchment in Denmark. The approach includes initial calibrations of three one-dimensional models representing the three land surface types using the flux measurements for calibration. This step provides initial values for the subsequent modelling and calibration at catchment scale. To test the validity of the approach, two additional catchment scale distributed simulations were performed with no calibration and only calibration of the one-dimensional models, respectively. In addition, a subsequent validation period was simulated. A mean energy closure imbalance of $20 \%$ was seen for the three sites. For the distributed simulations, the energy imbalance was accounted for by two energy balance closure hypotheses ascribing the error to either energy fluxes or net radiation. In general, the distributed calibration approach improved model results substantially compared to using default values (no calibration) or calibration of the one-dimensional models only. For the distributed model simulations, the assumption regarding the energy balance closure had a substantial impact on the parameter sensitivities and on the simulated discharge and energy balance. During calibration, the simulation with corrected energy fluxes showed better performance on discharge than the simulation with corrected net radiation whereas the reverse was true for the validation period. Regarding energy fluxes, the simulation with corrected net radiation was superior in both the calibration and validation period. 

Dear Editor

With great pleasure we hereby submit or research paper "Calibration of a distributed hydrology and land surface model using energy flux measurements" for consideration in the Journal of Agricultural and Forest Meteorology.

Traditionally, distributed hydrology models often rely on potential evapotranspiration to estimate actual evapotranspiration rather than solving the energy equation. SVATs and LSMs on the other hand do solve the energy equation and are often calibrated in 1D or uses remote sensing data in distributed setups.

With the present paper we present a novel approach to calibrating a combined spatially distributed hydrology-land surface model using energy flux tower observations in combination with discharge reaching good results.

The present paper is not a resubmission and has no concurrent submissions to other journals.

Sincerely, Morten A D Larsen, corresponding author, madla@dtu.dk/+4525119895 
Ms. Ref. No.: AGRFORMET-D-15-00325

Title: Calibration of a distributed hydrology and land surface model using energy flux measurements Agricultural and Forest Meteorology

I have now completed the review of the above manuscript. I apologize for the unusually long review time. We invited 14 different reviewers to assess your work. I have decided to make a decision based on one review and my own assessment of your manuscript.

In my opinion, the manuscript is extremely well written and addresses an important topic. I appreciate the objective and rigorous calibration approach and the testing of the models at the eddy covariance sites and catchment scales. This manuscript was a pleasure to read. I have a few minor comments/questions:

\section{Dear editor/co-editor and reviewers}

Thank you for considering our manuscript, the overall positive critique, the large effort in finding reviewers and the reviews itself which address important points even in the light of the suggested "minor review". Below you find a comment by comment reply to the points raised by the two reviewers.

Best regards,

Morten A. D. Larsen

1. I wondered how much of the ag land is tile drained and how this might influence the model performance compared to the non ag lands?

Being a part of the DK-model nationwide MIKE SHE setup a global (100\% coverage) drainage is used since the dense network of smaller streams and ditches cannot be resolved by the $500 \mathrm{~m}$ resolution. The differences between land surface types should therefore be minimal. The drainage is described in:

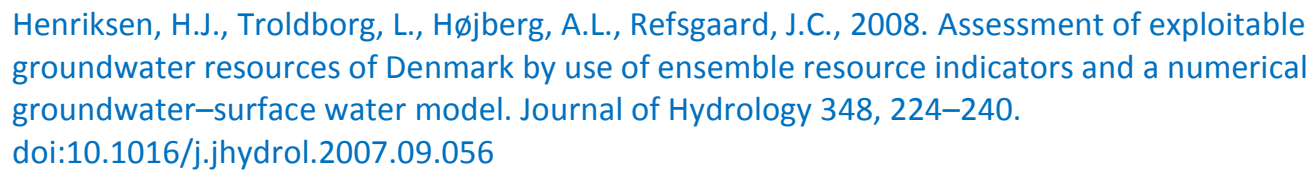

At the scale in question the setup is capable of reproducing observed physical variables such as discharge, groundwater heads and soil moisture due to rigorous calibration and refinement during the last 12-15 years. We do not have information on the exact share of drained land over the agricultural areas within the catchment, but refer to technical papers on the performance of specific output variables:

Henriksen, H.J., Troldborg, L., Nyegaard, P., Sonnenborg, T.O., Refsgaard, J.C., Madsen, B., 2003. Methodology for construction, calibration and validation of a national hydrological model for Denmark. Journal of Hydrology 280, 52-71. doi:10.1016/S0022-1694(03)00186-0

2. Line 193. you mention simulated irrigation, but it is not clear how much water this adds to the system or how you determined the simulated amount. Further, how much uncertainty does this add to your analysis?

The irrigation is calculated in the MIKE SHE model code on the basis of knowledge on well locations, filter depths, known annual abstraction, a demand area and agricultural land around each well by a demand function and a simulated water deficit in the root zone as described in: 
Stisen, S., Sonnenborg, T.O., Højberg, A.L., Troldborg, L., Refsgaard, J.C., 2011b. Evaluation of Climate 748 Input Biases and Water Balance Issues Using a Coupled Surface-Subsurface Model. Vadose Zone

J. 10, 749 37. doi:10.2136/vzj2010.0001

To be able to add irrigation to the precipitation file, these simulations have however been performed prior to the simulations were results are extracted for this manuscript. We agree that this is currently not clear in the manuscript and have revised accordingly. Good suggestion.

3. You do a nice job assessing the impact of lack of energy balance closure and showing the sensitivity to such assumptions. I recommend you include in your discussion some of Alan Barr's work.

Energy balance closure at the BERMS flux towers in relation to the water balance of the White Gull Creek watershed 1999-2009

By: Barr, A. G.; van der Kamp, G.; Black, T. A.; et al.

AGRICULTURAL AND FOREST METEOROLOGY Volume: 153 Special Issue: SI Pages: 3-13

Published: FEB 152012

Thank you very much. We have been aware that some would might think the paper is on the heavy side with regards to the number of references which is partly caused by the literature study on parameter values. Other than the included studies on parameter values, the number of studies on energy balance closure is of course vast and the number of references to include among these is a subjective matter. We are glad to be made aware of this study and definitely agree that it should be included due the catchment scale, energy balance considerations, the long evaluation period and streamflow evaluation. This is done.

It would be helpful to me if you could return the reviews annotated, in a different colour or font, to indicate how you have responded to each of the comments.

I am not sure if you mean in the response letter or in a manuscript version but I do both to make sure: In the present document I answer each comment separately and point out where I have applied the corrections and I also attach a manuscript version with corrections highlighted. 
Reviewers' comments:

Reviewer \#1: Summary of Paper:

The objective of this work is to develop a method for parameter calibration of a spatially distributed hydrologic model using both energy fluxes and catchment runoff. The study used the MIKE SHE hydrologic model and the SWET land surface model. The authors conducted a parameter sensitivity test (Monte-Carlo) and presented four stepwise calibration schemes.

Main impression:

The approach used in this paper was novel, complex, and adds great understanding to the parameterization of distributed hydrologic models. Their results do show an overall improvement in the simulated energy balance post-calibration. I would suggest very minor edits/additions prior to publication.

As also stated above - we would like to thank for the effort in reviewing and the positive judgement of the paper.

Specific Comments and Suggestions:

1. $\quad$ L22: "...the three land surface types and using the flux measurements for calibration." I am not sure what is suggested here? The above text is exactly equal to the manuscript and can therefore not be seen as a suggestion for a change. After reading the sentence again I can see that the "and" could be removed which could have been the intent of the suggestion. This is done.

2. L29: Are you referring to the calibration approach of the distributed systems? Yes - this is specified.

3. L46: Explain acronyms before use. We agree fully but these are model names which was not clear. This is therefore clarified.

4. L94-95: Sentence error.

That sentence was indeed uneasy. It was corrected in relation to including a reference as suggested by the editor:

(Barr, A.G., van der Kamp, G., Black, T.A., McCaughey, J.H., Nesic, Z., 2012. Energy balance closure at the BERMS flux towers in relation to the water balance of the White Gull Creek watershed 19992009. Agric. Forest Meteorol. 153, 3-13. doi:10.1016/j.agrformet.2011.05.017).

5. L130: Referring the outlier and replacement data in Line 130 - Can the authors expand on how much data was considered an outlier and removed in the results section? Or was any data removed from the calibration/validation periods? This is important since both periods are only 1 year.

We agree that this could potentially infer with the quality of the calibration results and could be addressed in quantitative terms in addition to using the reference (Ringgard et al. 2012). For the calibration period the LE outliers made up $0.16 \%, 0.74 \%, 0.13 \%$ of the data material for Agriculture, forest and meadow respectively and for $\mathrm{H}$ the corresponding numbers were $0.05 \%, 0.8 \%$ and $0.15 \%$. In essence a relative small portion of the data. We have added the outlier-replaced percentage between LE and $\mathrm{H}$ to the text (weighted average between stations). 
6. Section 4.2 - By this section I already forgot about what HYP1, 2, 3, 4 represented as far as the calibration scheme. Adding a short sentence reminding the reader about the calibration approaches would be helpful.

Good suggestion. This is added.

7. Figure 4. Agriculture - Root shape parameter - I'm a little baffled as to how the input scenarios affect the parameter sensitivity so much as to designate the parameter highly sensitive for HYP1 and HYP4 (100\% sensitivity), and moderately sensitive $(<40 \%)$ for the other two scenarios. This is the same site, the inputs should not be so different.

We agree that from an immediate understanding the difference should not be in this range. More conditions could however attribute to this:

- The sensitivities are relative and therefore the change in relative root shape (A_root) sensitivity can be caused by changes in sensitivities for other parameters - in this case Rst_min.

- The processes are highly non-linear causing this shift when using either corrected (HYP1 and HYP4) or uncorrected fluxes (HYP2 and HYP3).

- The root shape parameter controls the distribution of root water uptake from either the upper or lower part of the root zone. Thus, it appears that this parameter, as opposed to root depth, is the most effective when adjusting for a simulated reproduction of actual evapotranspiration.

8. $\quad$ Figure 8. Add $x$ and $y$ labels

We have only written labels once, since they are equal for all three figures. We have however changed the layout slightly to more clearly reflect this.

For further assistance, please visit our customer support site at http://help.elsevier.com/app/answers/list/p/7923. Here you can search for solutions on a range of topics. You will also find our $24 / 7$ support contact details should you need any further assistance from one of our customer support representatives. 


\section{Highlights}

- A new hydrology model calibration approach solving the energy equation is proposed.

- Initial 1D calibration is performed on three representative flux tower sites.

- $\mathrm{LE}+\mathrm{H}+\mathrm{G}$ were $20 \%$ below $\mathrm{Rn}$ requiring two hypotheses on the erroneous component.

- The approach was skilful - validated against runs with fewer calibration steps.

- The hypothesis ascribing Rn error was superior over the $\mathrm{LE}+\mathrm{H}+\mathrm{G}$ error hypothesis. 


\section{Calibration of a distributed hydrology and land surface model using energy flux}

\section{2 measurements}

Morten A. D. Larsen ${ }^{1 *}$, Jens C. Refsgaard ${ }^{2}$, Karsten H. Jensen ${ }^{3}$, Michael B. Butts ${ }^{4}$, Simon Stisen $^{2}$ and Mikkel Mollerup ${ }^{5}$.

61 - Technical University of Denmark, Department of Management Engineering, Frederiksborgvej 399, 4000 Roskilde,

7 Denmark

82 - Geological Survey of Denmark and Greenland, Øster Voldgade 10, 1350 Copenhagen, Denmark.

93 - University of Copenhagen, Department of Geosciences and Natural Resource Management, Øster Voldgade 10,

101350 Copenhagen, Denmark.

114 - DHI, Agern Alle 5, DK 2970, Hørsholm, Denmark

5 - The Danish Road Directorate, Guldalderen 12, 2640 Hedehusene.

* - Corresponding author: madla@dtu.dk/004525119895

Keywords: hydrology/land surface modelling; calibration; water and energy fluxes;

evapotranspiration; energy closure imbalance

\section{Abstract}

In this study we develop and test a calibration approach on a spatially distributed groundwater-surface water catchment model (MIKE SHE) coupled to a land surface model component with particular focus on the water and energy fluxes. The model is calibrated against time series of eddy flux measurements from three sites of different land surface type (agriculture, forest and meadow) and river discharge data from the $2500 \mathrm{~km}^{2}$ Skjern River catchment in

Denmark. The approach includes initial calibrations of three one-dimensional models representing

the three land surface types using the flux measurements for calibration. This step provides initial 
values for the subsequent modelling and calibration at catchment scale. To test the validity of the approach, two additional catchment scale distributed simulations were performed with no calibration and only calibration of the one-dimensional models, respectively. In addition, a subsequent validation period was simulated. A mean energy closure imbalance of $20 \%$ was seen for the three sites. For the distributed simulations, the energy imbalance was accounted for by two energy balance closure hypotheses ascribing the error to either energy fluxes or net radiation. In general, the distributed calibration approach improved model results substantially compared to using default values (no calibration) or calibration of the one-dimensional models only. For the distributed model simulations, the assumption regarding the energy balance closure had a substantial impact on the parameter sensitivities and on the simulated discharge and energy balance. During calibration, the simulation with corrected energy fluxes showed better performance on discharge than the simulation with corrected net radiation whereas the reverse was true for the validation period. Regarding energy fluxes, the simulation with corrected net radiation was superior in both the calibration and validation period.

\section{Introduction}

Water and energy fluxes between land surface and atmosphere are important components of atmospheric and hydrological processes. These fluxes can be quantified by the use of land surface models (LSM) or soil-vegetation-atmosphere-transfer models (SVAT). The calculation of e.g. evapotranspiration in SVATs and LSMs is based on solving the energy and radiation equations often on a sub-daily basis and they therefore differ from the less physically stringent schemes often used in many traditional hydrological models which are based on potential evapotranspiration. LSMs, originating from atmospheric sciences, include spatially distributed, often large scale descriptions of land surface processes. Examples include the Noah model (Rosero et al. 2010) and the CLM model 
(Lawrence et al. 2011). LSMs are typically coupled with or forced by atmospheric models and have recently been included in fully coupled climate-hydrology models (Maxwell et al. 2011, Shrestra et al. 2014). SVATs, originating from soil and hydrological sciences, are one-dimensional descriptions typically used for small-scale descriptions linked with soil water flow models (Mauser and Schädlich 1998, Ridler et al. 2012). When included in spatially distributed hydrological models they possess the potential for providing improved evapotranspiration descriptions and enable hydrological catchment models to better utilise remote sensing data to force and constrain hydrological models (Stisen et al. 2011a). SVATs have also recently been included in fully coupled climate-hydrology models (Butts et al. 2014, Larsen et al. 2014). LSMs and SVATs linked to spatially distributed hydrological models are basically similar, and hence we shall in the following refer to both of them as SVAT models.

Assessment of parameter values is critical for the use of SVAT models and an essential challenge is related the vast number of parameters often seen in this type of models. Franks et al. (1997, 1999), Beven and Franks (1999) and Gupta et al. (1999) all highlight the high uncertainty in the predictive capabilities of multi-parameter SVATs due to equifinality. Yet; Franks et al. (1997, 1999) still show good results in terms of reproducing point site flux measurements from the FIFE area in Kansas, USA, and in the Amazon area in Brazil. The added value of a multi-criteria approach as opposed to a single criterion method is confirmed by Gupta et al. (1999) and Demarty et al. (2004). Pollacco et al. (2013) apply an objective function weighing algorithm based on the uncertainties related to remote sensing based surface soil moisture and evapotranspiration calibration variables. Currently no explicit guidelines have been developed on calibrating complex and distributed SVAT and hydrology models.

Parameter estimation for hydrological models is traditionally performed by use of calibration where parameter values are modified to obtain best possible fit between model 
simulations and observed target data. While calibration was previously often performed manually by a trial-and-error approach, parameter optimisation by inverse modelling is now the method of choice (Gupta et al. 1998, Madsen 2003, Moore and Doherty 2005). An example is the study by Sun et al. (2013) where inverse calibration based on Monte Carlo-Bayesian techniques was used for calibrating a model both against energy fluxes at point scale and runoff at catchment scale (4.9 $\mathrm{km}^{2}$ ). In Ingwersen et al. (2011) inverse calibration was used to simulate the water and energy budget for a winter wheat stand at plot scale. Similarly Ridler et al. (2012) utilized inverse techniques for calibrating the combined MIKE SHE/SWET model to simulate energy fluxes at point scale in Mali.

A particular problem related to calibration of SVAT models is that observations of water and energy fluxes are usually not available from operational monitoring networks but only from a few research stations and often for short periods (Wilson et al. 2002, Franssen et al. 2010, Leuning et al. 2012). In addition, energy flux data are known to often have problems with energy balance closure which severely hampers parameter optimisation by inverse modelling, as a SVAT model per definition assumes a closed energy balance (Twine et al. 2000, Choi et al. 2009) and a failure to meet this demand can result in significant biases in long term climate model simulations (Grimmond et al. 2010). Also, the lack of measured energy balance closure will yield an erroneous parameterization when the fluxes are used for the calibration of a hydrological model. Therefore certain assumptions need to be made to account for the lack of closure. To accommodate this, Beven (2006) suggested creating artificial hypotheses to provide closure.

Catchment water balances are linked to energy balances, because the latent energy/evapotranspiration appears as a key element in both balances. The observed catchment runoff and the catchment water balance assessed by hydrological models hence include important information also on the energy balance. On a catchment scale $\left(603 \mathrm{~km}^{2}\right)$ Barr et al. (2012) used 
distributed flux tower measurements of evapotranspiration against measured precipitation and discharge for a residual analysis on water balance closure concluding a $15 \%$ lack of energy flux closure compared to the measured net energy. For catchment scale $\left(205 \mathrm{~km}^{2}\right)$ model calibration, Li et al. (2011) used the CLM4 model, modified to include a runoff scheme, to evaluate both runoff and energy fluxes. Similarly, operating on a regional to continental scale Maurer et al. (2002) simulated energy flux components while the model was manually calibrated only against runoff.

The objectives of the present study is to develop and test a methodology for calibrating and assessing parameters of a SVAT model linked to a spatially distributed hydrological model by using observations of both energy fluxes and catchment runoff. A comprehensive literature study was carried out to obtain feasible initial values and range of variation for parameters for the considered land surface types. The impact of energy imbalance is of particular emphasis and we analyse to which extent inclusion of discharge observations in the calibration process will improve the model performance and robustness.

\section{Methodology}

\subsection{Study area and data}

The Skjern catchment $\left(2500 \mathrm{~km}^{2}\right)$ is located in the western part of the Jutland peninsula, Figure 1 . The catchment is dominated by sandy soils generated by glacial outwash plains from the last glacial period Weichsel and intersected by older till deposits from the previous glacial period Saalian (Greve et al. 2007). The topography reaches $130 \mathrm{~m}$ above sea level in the eastern part of the catchment and the Skjern River flow into Ringkøbing fjord at sea level to the west. The yearly average precipitation for the catchment is $940 \mathrm{~mm}$ for the period 2000-2009 based on direct measurements. When corrected for undercatch using standard monthly correction factors (Allerup et al. 1998) the average precipitation amounts to $1130 \mathrm{~mm}$. In the same period the mean annual 
temperature is $9.3{ }^{\circ} \mathrm{C}$ and the mean monthly temperatures range between 2.1 and $17.3{ }^{\circ} \mathrm{C}$. Inside the catchment flux towers are placed at the three predominant surface types; agriculture (61\%), meadow/grass (24\%) and forest (13\%), Figure 1. At all sites measurements of short-, long-wave and net radiation components; latent $(\mathrm{LE})$, sensible $(\mathrm{H})$ and soil heat fluxes $(\mathrm{G})$; soil water content; precipitation; air temperature; wind speed; and water table levels have been carried out since late 2008. Measurements of radiation and energy fluxes are based on standard methods. Radiation components are measured using a NR01 Hukseflux radiometer (www.hukseflux.com), LI-COR eddy covariance equipment is used for measuring LE fluxes, Gill sonic anemometers for measuring $\mathrm{H}$ fluxes, and Hukseflux plates for measuring G fluxes.

The energy flux data used in the study have undergone quality control as part of the processing (Ringgard, 2012) (Step 1.3, Figure 2). Inaccurate observations caused by e.g. low turbulence condition were replaced by data representing similar conditions. Replacement of data was thus for periods with low energy fluxes and therefore this source of uncertainty is expected to be of minor significance. Individual data points clearly outside the expected range at the time of day and season were considered as outliers and removed (equal to $0.2 \%$ on average between LE, $\mathrm{H}$ and the three stations weighted relative the areal share). For two periods July 21-August 16 and August 24-October 28, 2009, no flux measurements were available from the agricultural site and data were replaced from the forest site. As these periods are mostly placed in the spin-up period (see below) the calibration results are not expected to be significantly affected.

\subsection{Modelling system and setup}

This study uses the spatially distributed MIKE SHE hydrological modelling system capable of including all key hydrological processes such as ET, channel flow, overland flow, unsaturated flow, saturated flow as well as irrigation and drainage (Graham and Butts 2005). The land surface 
model SWET component (Overgaard, 2005) is used in the analysis. SWET is based on the Shuttleworth-Wallace model (Shuttleworth and Wallace 1985). It considers vegetation and energy balance processes in a two-layer system and is extended to include energy fluxes from ponded water and interception storage. Models are constructed for both the three local measurement sites (1D representation) and for the entire catchment (Figure 1).

The 1D models simulate energy fluxes and vertical unsaturated flow based on Richards' equation. The SWET model is driven by 30 min climatic observations of precipitation, air temperature, wind speed, net radiation, surface air pressure and relative humidity. Measured water table elevations are specified as lower boundary condition. As opposed to the fully distributed model application overland flow, river flow and groundwater flow are not considered. Relevant to both the 1D and distributed analyses, the SWET land-surface module does not consider snow accumulation and melting. Initial values for root depth and vegetation height applicable for the 1D simulations of the agricultural and meadow sites were based on estimates from model simulations for relevant soil type and management conditions using the vegetation model Daisy (Styczen et al. 2004a). Since the footprint of the flux tower at the agricultural site was influenced by several crop types, the vegetation height and root depth were based on average simulations for winter- and spring cereals. The observational data for leaf area index (LAI), another important crop parameter, was inconsistent, and the seasonal variation of this parameter was therefore derived by combining the observed seasonal trends and the simulation results by the Daisy model. The initial values for soil parameters for each site were derived from the HYPRES pedotransfer function (Wösten et al. 1999). Specifically, the Van Genuchten parameters $\alpha$ and n (van Genuchten, 1980) as well as saturated hydraulic conductivity, residual- and saturated water content were estimated from soil texture, organic matter and bulk density. The soil texture data were retrieved from grid values from a distributed soil map of $250 \mathrm{~m}$ resolution in the A horizon $(0-30 \mathrm{~cm})$ and $500 \mathrm{~m}$ resolution in B and 
C horizons (30-80 cm and below $80 \mathrm{~cm}$ ) (Styczen et al. 2004b, Greve et al. 2007, Iversen et al. 2011). For the sensitivity and optimization analyses the soil parameter bounds were defined by calculating the $90 \%$ confidence intervals of variation ranges from Meyer et al. (1997) for soils of similar texture as for the three field sites. These soil types include sand, loamy sand and sandy loam for the agriculture and forest site roughly corresponding to JB1 soil (coarse sand) in the Danish soil classification system (Greve et al. 2007, www.djfgeodata.dk). Due to the lack of agreement on soil type at the meadow site between site specific soil retention data and available soil maps the $90 \%$ confidence intervals for the meadow site is based on a wider range of soil types from loamy sand to clay loam (Meyer et al. 1997). The discrepancy of the data is most likely due to highly heterogeneous soils caused by shifting alluvial deposits from the nearby Skjern River. In the parameterization the seasonal patterns of vegetation characteristics as induced by both climate and management practice were kept constant whereas the respective amplitudes were calibrated by a single factor for each parameter. The annual sequence of these ratios was found by balancing model simulations by Daisy, relevant literature values (Table 1) and occasional on-site measurements of LAI and vegetation height. Similarly, the relation between the parameter values in the three vertical soil type horizons were kept constant implying that the individual parameters for the A, B and C horizon were shifted by the same factor for each grid cell. By introducing factors between parameters in space and time the number of parameters to be optimized is reduced.

The MIKE SHE model for catchment scale is based on the Danish national water resources model (DK-model) (Stisen et al. 2012, Højberg et al. 2013). As opposed to the DK-model the present model includes the SWET land-surface model and the parameterization of this model is partly based on the work by Stisen et al. (2011a). The DK model has a $500 \mathrm{~m}$ resolution and includes a detailed river network. A maximum time step of 1 hour is used for overland, unsaturated and saturated flow. The MIKE 11 open channel river model component utilizes 3616 cross sections 
in 100 river branches and uses a 30 min time step. For precipitation exceeding $2 \mathrm{~mm}$ per time step an automatic reduction in time step takes place. The input for the catchment scale SWET model is hourly values of the same climatic variables as for the 1D models. These values are obtained by thin plate spline interpolation of climate station data (Stisen et al. 2011a) to a resulting grid in $2 \mathrm{~km}$ resolution for all variables except precipitation used in $500 \mathrm{~m}$ resolution. Precipitation input is based on interpolation of daily rain gauge data using kriging and dynamically corrected for undercatch. Hereafter, simulated irrigation is added to the precipitation input file. The simulated irrigation is calculated from the root zone deficit and a demand function based on well locations, filter depths, annual abstractions and demand area information (Stisen et al. 2011b). The agricultural crop distribution was developed from statistical data, where the various crops were grouped in four classes with different growth characteristics: spring sown cereals, winter sown cereals, grass/clover and maize. The crop classes were distributed without georeferencing due to lack of data. Forest vegetation parameters were based on relevant literature and observations. A total of 36 parameters were analysed in the sensitivity analysis. As the calibration is targeted towards the energy fluxes no sensitivity and calibration analyses are performed on the saturated zone parameterization which is already well calibrated as a part of the DK-model (Stisen et al. 2012, Højberg et al. 2013).

To generate proper initial conditions for soil moisture in the 1D simulations a spin-up period of 5-10 months prior to the calibration period was used. The spin-up periods were decided by data availability as measurements started in April 2009 for the agriculture and meadow sites and December 2008 for the forest site. The distributed model involves a considerable increase in computation time compared to the 1D setups and a spin-up period of 3 months was therefore used. Groundwater quasi steady-state was reached by looping simulations in 3-year runs each time using 
the resulting groundwater heads as initial conditions for the subsequent simulation. Three loops were required to reach quasi steady-state.

\subsection{Calibration approach}

We propose a calibration and validation approach involving three steps as illustrated in Figure 2: (1) calibration of 1D models representing the flux measurement sites, (2) use of parameter values from step 1 as initial values in the calibration of the distributed catchment model, and (3) validation of the distributed parameterization on independent data. Additionally we test the calibration results by comparing to model results based on $1 \mathrm{D}$ calibration only and with no calibration respectively.

Both the $1 \mathrm{D}$ and the distributed simulations were calibrated using inverse modelling adopting initial and range of parameter values from literature, observations, databases and simulation results from the model code Daisy (Hansen et al. 1990, 1991) as described above and as listed in Table 1 and 2. The initial input parameter values as well as their ranges were specified according to relevance: If available, either observations or Daisy model simulations based on site specific conditions were used. When using literature values conditions similar to the sites in terms of vegetation species, climate and soil type were used. The calibration period covers a one year period from October 1, 2009 to September 30, 2010 while the validation period is from May 1, 2011 to April 30, 2012.

The sensitivity and auto-calibration analyses were performed using the AUTOCAL software included in the MIKE SHE package (Madsen 2003). At the point scale three components were included in the objective function: latent heat flux LE, sensible heat flux $\mathrm{H}$, and averaged soil water content based on measurements at three depths $(2.5,22.5$ and $52.5 \mathrm{~cm}$ below the surface). The objective function was built from the root mean square errors (RMSE) between observations and 
simulations. The RMSEs for the three individual components were normalized, weighted equally and summed to arrive at an aggregated objective function. The normalization was carried out using the common distance scale which has proven to be robust in accounting for differences in magnitude of each component of the objective function (Madsen 2003, Butts et al. 2004, Mertens et al. 2004).

At catchment scale the optimization was performed against two overall components of equal weight: (1) Discharge observations at three discharge stations aggregated with equal weight (Figure 1) and (2) latent and sensible energy fluxes at the three sites weighted according to the relative areal share of each land surface type (agriculture 62\%, forest $13 \%$ and grass/meadow $25 \%$ ).

The sensitivity analysis (Step 1.2 and 2.2 in Figure 2) for both point and catchment scales were based on the AUTOCAL local sensitivity analysis procedure accounting for parameter sensitivities at the location in parameter space defined by the initial parameter values. Since the sensitivity analysis was local and therefore unable to account for numerous combinations in the parameter space, the sensitivity analyses were repeated using randomly sampled parameter sets within the parameter bounds. The sensitivity analysis was based on a backward difference approximation method around the parameter value using a $2 \%$ perturbation fraction. Also, covariance matrices were calculated to test for parameter correlation.

For both scales the ten most sensitive parameters were identified and subsequently used in the auto-calibration process similar to Blasone et al. (2007). Only parameters with relative sensitivity coefficients above $1 \%$, in relation to the most sensitive parameter, were included in the optimization (Hill 1998). For the low sensitivity parameters that were not included in the autocalibration of the catchment model their values were derived from the point scale calibrations. The remaining distributed parameters were based on relevant literature (Table 2). 
The point scale parameter optimization was based on the global Shuffled Complex

Evolution method (Duan et al. 1993) which has proven to be robust for comprehensive parameter estimation problems (Butts et al. 2004, Mertens et al. 2005, Blasone et al. 2007). A maximum time step of 6 minutes was used for the 1D models, which for the calibration period corresponded to a computation time of around 2-3 minutes per model run. The model convergence criteria were defined as max. $1 \%$ change in objective function after three iterations loops and this criterion was usually met after 200-250 runs. For obtaining a more efficient optimization of the catchment scale model, parallel model runs were carried out using the global Population Simplex Evolution optimization method (DHI 2010). The convergence criterion was typically reached after 250-400 runs.

To assess the accuracy of the parameterization and modelling approach as such, an independent validation analysis was performed subsequent to the auto-calibration simulations. The validation was performed for a one-year period and assessed on discharge, LE and $\mathrm{H}$ as for the calibration analysis (Step 3.1, Figure 2).

\subsection{Handling of Energy Balance Flux problems}

Energy balance closure requires that the net radiation (difference between incoming and outgoing long- and short-wave radiation) equals the sum of latent heat (LE), sensible heat (H), and soil heat $(\mathrm{G})$ fluxes. All terms are highly sensitive to the surface characteristics and furthermore they are subject to different diurnal and seasonal variations. The albedo of bare soil is dependent on texture and moisture content while the albedo for vegetation generally decreases with vegetation height and stand complexity. Changes in albedo will affect the amount of available energy, and soil moisture influences how this energy is distributed between LE and $\mathrm{H}$ heat fluxes. Independent measurements of the components of the energy balance equation rarely provide closure, which has 
been documented in numerous studies (Wilson et al. 2002, Franssen et al. 2010, Leuning et al. 2012).

The impact of the energy balance closure problem on the calibration results was addressed by creating four hypotheses each based on different assumptions regarding measurement errors (Step 1.4 and 2.4, Figure 2). All four hypotheses were used for the 1D runs whereas only the first two were used in the distributed runs to reduce computation time.

- HYP1: The measured energy fluxes (LE, $\mathrm{H}$ and $\mathrm{G}$ ) are scaled with a single factor (increase) such that the Bowen-ratio is maintained and the sum of the energy fluxes equals measured net radiation over the one-year calibration period;

- HYP2: The measured energy fluxes are maintained whereas the net radiation is scaled with a factor (reduction) to match the sum of measured energy fluxes over the one-year calibration period;

HYP3: The measured energy fluxes are unaltered whereas the sum of these is used as net radiation on a daily basis;

- $\quad$ HYP4: The measured energy fluxes (LE, H and G) are scaled with a single factor (increase) such that the Bowen-ratio is maintained and the sum of the energy fluxes equals measured net radiation on a daily basis;

For the first two scenarios the entire dataset is multiplied by a single scaling factor to provide energy closure for the one year calibration period. Closure on a daily basis may not be met, which is the case for the last two scenarios. Of the investigated scenarios more energy is available in HYP1 and HYP4 based on the measured net radiation (yearly mean values of $55 \mathrm{w} / \mathrm{m}^{2}, 68 \mathrm{w} / \mathrm{m}^{2}$ and $55 \mathrm{w} / \mathrm{m}^{2}$ for agriculture, forest and meadow respectively) whereas HYP2 and HYP3 are based on reduced values (yearly mean values of $39 \mathrm{w} / \mathrm{m}^{2}, 48 \mathrm{w} / \mathrm{m}^{2}$ and $42 \mathrm{w} / \mathrm{m}^{2}$ for the same sites). 

both utilize measured net radiation, scaled and unscaled, and hereby the daily temporal pattern is

likely to be more representative than if based on the sum of the three fluxes. In contrast to the point scale where net radiation measurements were available, global radiation was used in the catchment scale analysis. To fulfil the same assumptions on energy balance closure as used at point scale the albedo was adjusted to obtain energy balance closure over the entire one year calibration period. This was done based on the flux measurements for the three general land use types agriculture, forest and meadow. As a result HYP1 is based on measured albedos whereas HYP2 is based on estimated albedos that are higher than measured. All three distributed simulation cases shown in Figure 2 were performed for both HYP1 and HYP2 as well as for the calibration and validation periods for a total of 12 simulations.

\section{Results}

\subsection{Energy balance closure}

The measurements used in this study show lack of energy balance closure. The sum of LE, $\mathrm{H}$ and $\mathrm{G}$ over the one-year calibration period accounted for $71 \%, 71 \%$ and $76 \%$ of the measured net radiation at the agricultural, forest and meadow/grass sites respectively (Figure 3). The corresponding measured Bowen-ratios in the same period were $0.20,0.17$ and 0.18 for the three land surface types. Radiation and particularly data for energy fluxes are generally sparse in Denmark. Therefore, in Figure 3, measured net and global radiation as well as the sum of energy fluxes are compared to results from (1) the corresponding grid cell in HIRHAM regional climate model simulations (Larsen et al. 2013) using ERA-Interim reanalysis data as boundary conditions and (2) observation data from the Foulum research station (grass surface) located app. $50 \mathrm{~km}$ north of the agriculture and forest sites. HIRHAM simulation data are also used to compare LE and $\mathrm{H}$ 
fluxes since no other flux data were available. The simulations of net radiation by HIRHAM and the observed data from Foulum are much closer to measured LE, H and G flux sum at all sites for both years although perhaps less distinct at the forest site (Figure 3). For global radiation there is a close match between all data series, especially between the three study sites and Foulum. For LE fluxes good agreement is seen between HIRHAM simulations and observations for the forest and meadow sites and less favourable for the agricultural site. For the $\mathrm{H}$ fluxes larger discrepancies are seen particularly for the forest site.

\subsection{Simulation results}

The results of the sensitivity analyses for both point and catchment scales are shown in Figure 4. Similar parameter sensitivity results are obtained for the agricultural and forest sites with nine and ten parameters, respectively, having a relative sensitivity coefficient above $10 \%$. The parameter sensitivities for hypotheses HYP2 and HYP3 (with unaltered energy fluxes) show similar patterns with the minimal stomata resistance (Rst_min) as the most sensitive parameter. In contrast, for hypotheses HYP1 and HYP4 (with corrected energy fluxes) the root shape factor is the most sensitive parameter. For the meadow site only the three parameters Rst_min, leaf area index (LAI) and vegetation height have relative sensitivity coefficients above $10 \%$ and the influence of the energy balance hypothesis is limited given the large drop in sensitivity between Rst_min and the second most sensitive parameter LAI.

At catchment scale saturated hydraulic conductivity (K_sat) for the unsaturated zone is the most sensitive parameter for both energy balance hypotheses, whereas the sensitivities of the remaining parameters are smaller and also subject to larger variation between the two hypotheses (Figure 4). The forest energy fluxes were found to be poorly reproduced by the calibrated forest leaf width values which were therefore manually calibrated prior to auto-calibration. 
The simulated discharge based on the parameter values obtained by the full auto-calibration approach for the two distributed energy balance hypotheses are shown in Figure 5 for both the calibration and validation periods. For both simulations and periods there is a tendency of underestimation of baseflow and mostly pronounced for HYP2. For peak flow the HYP2 hypothesis exhibits more dynamic behaviour with more rapid responses. In summary, the HYP1 simulation shows better discharge performance statistics for the calibration period whereas the opposite pattern is seen for the validation period (Figure 6). Also, the validation confirms a reasonable discharge calibration although the HYP1 results are moderately poorer for two out of three discharge stations.

Figure 7 shows simulated LE and H energy fluxes on an hourly basis for a 10 day summer period in the calibration period. The results from the two energy hypothesis runs are compared to their relevant fluxes: HYP1 to scaled and HYP2 to unscaled fluxes, corresponding to the assumptions of the energy balance closure. For both the calibration and validation periods, there is a tendency for better energy flux statistics for HYP2 compared to HYP1 (Figure 6). Overall the agriculture and grass surfaces are better reproduced compared to forest. Especially observations of $\mathrm{H}$ in the forest are rather poorly simulated during high global radiation (Figure 7); however, part of this discrepancy is likely caused by errors in the observation data (Sonnenborg et al. 2013). Simulations for night time conditions compare favourably to observations of both energy fluxes and for both scenarios. As shown in Figure 6 the simulations for the validation period shows comparable or better performance statistics for both fluxes as compared to the calibration period.

In the auto-calibration, simulations are compared to the same observed discharge data for both HYP1 and HYP2 while the energy fluxes and albedos were adjusted to obtain energy balance closure. This is reflected by differences in water balance components for the two hypotheses HYP1 and HYP2 both on catchment and local scales (Table 3). With a lower albedo in the HYP1 scenario higher ET and therefore lower recharge and discharge are simulated at catchment scale. For the 
agriculture grid cell the slightly higher ET for the HYP2 hypothesis can be ascribed to the lower K_sat value. The significant difference in drainage is likely a function of higher groundwater elevations in the HYP2 hypothesis. For forest and meadow the difference in albedo is reflected in higher ET for HYP1.

The comparison of the performances of the full calibration and the scenarios with calibration of the 1D models only and no calibration respectively is shown in figure 6. For discharge the simulations with no calibration using default values is comparable to the results of the full calibration whereas the 1D calibration is generally poorer. The most significant improvement in the calibration approach is however seen for the LE and $\mathrm{H}$ energy fluxes where the mean root mean square error (RMSE) and mean absolute error (MAE) statistics for the three sites is substantially improved. The distributed simulations based on the values from the $1 \mathrm{D}$ calibration transferred to catchment scale are generally of lower quality compared to the case where no calibration is carried out. This, as opposed to using initial values using no calibration at all (default values), is because neither input source includes parameters related to the distributed scale (e.g. related to discharge and overland flow). Also, the extreme 1D mean RMSE statistics for $\mathrm{H}$ is due to the forest site which was manually calibrated prior to the autocalibration (see above) and it does therefore not affect the full 1D+2D calibration.

\section{Discussion}

We have presented an approach for a stepwise calibration of a distributed combined land surface/hydrology model using observations of energy fluxes and discharge as calibration target. In general the method proved effective. The validation period confirmed the performance statistics from the calibration period and the simulations using a reduced calibration approach or no calibration were generally less accurate. 


\subsection{Energy and water balance}

As expected a key finding was that the choice of energy balance hypothesis has a major impact on the resulting parameterization as well as on the energy and water balance results. The

lack of energy balance closure for flux measurements is therefore a great challenge when using such measurements for calibrating distributed hydrological models. Energy balance closure is required when flux measurements are used for inverse modelling and we investigated two hypotheses where the error was attributed to either the measured energy fluxes (HYP1) or the measured net radiation (HYP2).

Either of these two approaches may be applicable. Even though the eddy covariance method is generally regarded as the best practical method for measuring energy fluxes, measurement difficulties are well documented (Foken et al. 2006, Sun et al. 2008, Franssen et al. 2010, Ringgard, 2012, Stoy et al. 2013). A consistent deficit in measured LE fluxes have been suggested as an explanation in the lack of energy balance closure (Sun et al. 2008) while on the other hand Foken et al. (2006) suggested that low frequency turbulence structures cause errors in the flux measurements. Also, measurement errors in $\mathrm{H}$ fluxes have been suggested, see (Mauder et al. 2008) and Sonnenborg et al. (2013). The energy flux statistics (Figure 6) were better for the HYP2 hypothesis possibly indicating that larger measurement errors are attributed to the energy fluxes compared to radiation components. An additional contributing factor is the difference in the footprint of the flux measurements reflecting conditions upstream of the wind direction and the support scale of the radiation sensor.

Contrary to indications of flux measurement biases, estimates of ET based on eddy covariance and soil moisture balances of the root zone compared well and surprisingly the highest ET was seen for the eddy covariance method over a seven week period in May-June 2009 (Schelde 
et al. 2011). Similarly, net radiation measurements from Foulum research station match the sum of LE, $H$ and $G$ fluxes better than for the agriculture, forest and meadow sites used in this study (Figure 3). Advection has also been suggested as a missing component in the energy balance suggesting that the measured energy fluxes may indeed be more reliable than anticipated (Leuning et al. 2012). Likewise, large scale eddies due to land surface heterogeneity have recently been suggested to make up a part of the energy imbalance (Stoy et al. 2013).

Snow processes are currently not considered the SWET land-surface model and this impacts the calibration results especially with regard to discharge. Even though the calibration period is relatively cold, little precipitation occurs on days with temperatures below $0{ }^{0} \mathrm{C}$. Nevertheless, the snow melt related discharge peaks in Feb-Mar 2010 are clearly not reproduced (Figure 5).

\subsection{Sensitivity, calibration and validation}

The distinct differences between parameter sensitivities at the agriculture and forest sites compared to the meadow site are related to the water available for ET (Figure 8). At the agricultural and forest sites, complete soil saturation is rarely or never reached and there is a clear tendency for higher ET with lower soil moisture as this occurs during the summer months with a higher level of available solar energy. Soil parameters affecting available soil water are therefore crucial for determining the partitioning of energy fluxes at these sites. For the meadow site, located next to the river bank, saturated conditions are often reached (41\% of the year for HYP2) and soil moisture levels are generally high. As a result the relation between root zone water and ET is less distinct. The high water availability at the meadow site therefore makes vegetation parameters substantially more important compared to soil parameters.

The choice of energy balance closure hypothesis, and therefore the energy available, is highly influential on which parameters are most sensitive especially for the agriculture and forest 
sites but also to some extent for the meadow site. This is reflected in the sensitivities for the HYP1 and HYP4 hypotheses on one side and the HYP2 and HYP3 hypotheses on the other. This is consistent with the HYP1/HYP4 hypotheses being based on measured net radiation (averaged to 54, 67 and $56 \mathrm{~W} / \mathrm{m}^{2}$ in the calibration period for agriculture, forest and meadow) while the HYP2/HYP3 hypotheses are based on downscaled net radiation $\left(40,47\right.$ and $40 \mathrm{~W} / \mathrm{m}^{2}$ for the same sites).

The results of the sensitivity analysis and auto-calibration procedure naturally reflect the interplay between a vast number of parameters, assumptions regarding the energy balance terms, assumed relations between parameters for the individual soil layers, and the specific conditions that apply for the period subject to the analysis. These assumptions are required for reasons such as energy balance closure, calibration simplicity, data availability and focus of the study in question. For example, the parameter Rst_min is assumed constant in the present study whereas Ingwersen et al. (2011) obtained better simulations of LE and H based on the Noah LSM model using monthly values of Rst_min. Hou et al. (2012) related simulations of LE and H to parameter uncertainty in a study using the Community Land Model (CLM4) and documented substantial variations in the simulations of both fluxes (over $100 \mathrm{~W} / \mathrm{m}^{2}$ ) in the summer months depending on the parameterization. The rather poor agreement between simulations and observations of $\mathrm{H}$ fluxes was likely due to observation errors. Separate auto-calibration runs were performed assessing forest heat fluxes based on forest parameterization alone with limited improvement and this is in line with the results by Sonnenborg et al. (2013).

\subsection{Land use}

Standard seasonal crop characteristics were used in this study and the actual crop rotation and management conditions at a given site were therefor not considered. This could lead to 
discrepancies between the vegetation parameterization at the agricultural site particular around the time of harvest and at the grass site due to irregular and undocumented cattle grazing. Possibly more significant is the effect of the spatial distribution of crops derived from available county average data, which may not reflect the actual distribution. This is the case both in terms of the overall distribution, type and location of crops within the catchment. But it also affects the evaluation of energy flux data from the agricultural site as the actual footprint may differ from the simulated crop as also reported by Göckede et al. (2008).

The distributed MIKE SHE parameterization was performed by transferring the calibrated parameters from the point scale setups, representing agriculture, meadow and forest, to the relevant land surfaces within the catchment for subsequent sensitivity and auto-calibration analyses. For agriculture, this procedure includes the tradeoff between using the calibrated parameter values reflecting site specific conditions at the measurement site and using crop and soil specific parameters from the Daisy model. However, the former was used since parameters were calibrated under conditions of energy balance closure but also because of the statistical spatial distribution of the Daisy modelled crop characteristics.

\section{6 - Conclusions}

In the present study we present a novel approach to calibrating a combined and distributed hydrology/land-surface model. The approach first involves calibration of the land-surface model component against measurements of energy fluxes from flux towers. Secondly, the distributed hydrological model component, including unsaturated and saturated zone components, is calibrated using the point scale parameterization as initial conditions and using stream flow and energy flux measurements as the calibration targets. The method employs a meticulous literature inspection for realistic initial and range of parameter values. Previous calibration efforts of SVAT and LSM 
models with a hydrological focus have often used satellite data having certain measurement deficiencies, relied on previously point scale based parameterizations or used traditional hydrological variables such as discharge and hydraulic head. Modelling the highly interrelated and dynamical processes and variables in the entire water and energy budget from groundwater to lower atmosphere is challenging. Our results show that the proposed approach significantly improves the simulated energy balance components as compared to using default values or a simpler 1D calibration. The simulations were able to reproduce features across water and energy budgets taking into considerations measurement errors and lack of energy balance closure.

The calibration of the one dimensional models provided good insight to data quality and parameter sensitivity and served as a useful initial parameterization of the catchment scale simulations. Further, the sensitivities of parameters in the point scale analysis were highly affected by the surface type and more specifically the water availability as well as the choice of energy balance hypothesis. Similarly, the catchment model simulations showed that parameter sensitivities are largely determined by the choice of energy balance hypothesis, yet saturated hydraulic conductivity was the most sensitive parameter for both energy balance hypotheses. Despite likely errors in measured forest sensible heat fluxes, our results suggest that the measured energy fluxes are reliable and that the energy imbalance is likely caused by advection and large scale eddies rather than erroneous net radiation measurements.

\section{7 - Acknowledgments}

The present study was funded by a grant from the Danish Strategic Research Council for the project HYdrological Modelling for Assessing Climate Change Impacts at differeNT Scales (HYACINTSwww.hyacints.dk) under contract no: DSF-EnMi 2104-07-0008. The study is made possible 
through a collaboration with the HOBE project (www.hobecenter.dk) funded by the Villum Kann Rasmussen Foundation. The data used in the study can be accessed through the first author.

(1)

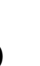

(1)

\section{8 - References}

- Allerup, P., Madsen, H., Vejen, F., 1998. Standardværdier (1961-90) af Nedbørkorrektioner, Danish Meteorological Institute Technical Report 98-10, Denmark.

- Barr, A.G., van der Kamp, G., Black, T.A., McCaughey, J.H., Nesic, Z., 2012. Energy balance closure at the BERMS flux towers in relation to the water balance of the White Gull Creek watershed 1999-2009. Agric. Forest Meteorol. 153, 3-13. doi:10.1016/j.agrformet.2011.05.017.

- Beier, C., Gundersen, P., Hansen, K., Rasmussen, L., 1995. Experimental manipulation of water and nutrient input to a Norway spruce plantation at Klosterhede, Denmark. Plant Soil 168, 613-622.

- Beven, K.J., Franks, S.W., 2001. Functional similarity in landscape scale SVAT modelling. Hydrol. Earth Syst. Sc. 3, 85-93. doi:10.5194/hess-3-85-1999

- Beven, K., 2006. Searching for the Holy Grail of scientific hydrology: Q t=(S, R,? t) A as closure. Hydrol. Earth Syst. Sc. Discussions 10, 609-618. doi:10.5194/hess-10-609-2006.

- Blasone, R. S., Madsen, H., Rosbjerg, D., 2007. Parameter estimation in distributed hydrological modelling: comparison of global and local optimisation techniques, Nord. Hydrol. 38(4-5), 451-476, doi:10.2166/nh.2007.024.

- Boulet, G., Kalma, J.D., Braud, I., Vauclin, M., 1999. An assessment of effective land surface parameterisation in regional-scale water balance studies. J. Hydrol. 217, 225-238.

- Breda, N.J.J., 2003. Ground-based measurements of leaf area index: a review of methods, instruments and current controversies. J. Exp. Bot. 54, 2403-2417. doi:10.1093/jxb/erg263 
- Butts, M. B., Payne, J. T., Kristensen, M., Madsen, H., 2004. An evaluation of the impact of model structure on hydrological modelling uncertainty for streamflow simulation, J. Hydrol. 298, 242-266, doi:10.1016/j.jhydrol.2004.03.042.

- Butts, M., Drews, M., Larsen, M.A.D., Lerer, S., Rasmussen, S.H., Grooss, J., Overgaard, J., Refsgaard, J.C., Christensen, O.B., Christensen, J.H., 2014. Embedding complex hydrology in the regional climate system - Dynamic coupling across different modelling domains. Adv. Water Resour. 74, 166-184. doi:10.1016/j.advwatres.2014.09.004

- Boegh, E., Poulsen, R.N., Butts, M., Abrahamsen, P., Dellwik, E., Hansen, S., Hasager, C.B., Ibrom, A., Loerup, J.-K., Pilegaard, K., Soegaard, H., 2009. Remote sensing based evapotranspiration and runoff modeling of agricultural, forest and urban flux sites in Denmark: From field to macro-scale. J. Hydrol. 377, 300-316. doi:10.1016/j.jhydrol.2009.08.029

- Chen, F., Dudhia, J., 2001a. Coupling an Advanced Land Surface-Hydrology Model with the Penn State-NCAR MM5 Modeling System. Part I: Model Implementation and Sensitivity. Mon. Wea. Rev. 129, 569-585. doi:10.1175/1520-0493(2001)129<0569:CAALSH>2.0.CO;2

- Choi, M., Kustas, W.P., Anderson, M.C., Allen, R.G., Li, F., Kjaersgaard, J.H., 2009. An intercomparison of three remote sensing-based surface energy balance algorithms over a corn and soybean production region (Iowa, U.S.) during SMACEX. Agric. For. Meteorol. 149, 2082-2097. doi:10.1016/j.agrformet.2009.07.002

- Crow, P., 2005. The Influence of Soils and Species on Tree Root Depth, Environmental and Human Sciences Division, Forest Research. ISBN 0-85538-679-7, United Kingdom.

- Dai, Z., Li, C., Trettin, C., Sun, G., Amatya, D., Li, H., 2010. Bi-criteria evaluation of the MIKE SHE model for a forested watershed on the South Carolina coastal plain. Hydrol. Earth Syst. Sc. 14, 10331046. doi:10.5194/hess-14-1033-2010.

- Demarty, J., Ottlé, C., Braud, I., Olioso, A., Frangi, J., Bastidas, L., Gupta, H., 2004. Using a multiobjective approach to retrieve information on surface properties used in a SVAT model. J. Hydrol. 287, 214-236. doi:10.1016/j.jhydrol.2003.10.003 
- DHI, 2010. AUTOCAL - Auto Calibration Tool, User Guide. MIKE by DHI Software, Hørsholm, Denmark.

- Duan, Q., Gupta, V. K., Sorooshian, S., 1993. A shuffled complex evolution approach for effective and efficient global minimization, J Optimiz. Theory. Ap., 76, 501-521.

- Ewers, B.E., Oren, R., Johnsen, K.H., Landsberg, J.J., 2001. Estimating maximum mean canopy stomatal conductance for use in models. Can. J. Forest Res. 31, 198-207. doi:10.1139/cjfr-31-2-198

- Foken T, Wimmer, F., Mauder, M., Thomas, C., Liebethal, C., 2006. Some aspects of the energy balance closure problem, Atmos. Chem. Phys., 6, 3381-3402, doi:10.5194/acp-6-4395-2006.

- Frank, A.B., Bittman, S., Johnson, D.A., 1996. Water relations of cool-season grasses. Cool-season Wisconsin, USA.

- Franks, S.W., Beven, K.J., Quinn, P.F., Wright, I.R., 1997. On the sensitivity of soil-vegetationatmosphere transfer (SVAT) schemes: equifinality and the problem of robust calibration. Agric. For. Meteorol. 86, 63-75. doi:10.1016/S0168-1923(96)02421-5

- Franks, S.W., Beven, K.J., Gash, J.H.C., 1999. Multi-objective conditioning of a simple SVAT model. Hydrol. Earth Syst. Sc. Discussions 3, 477-488.

- Franssen, H.J.H., Stöckli, R., Lehner, I., Rotenberg, E., Seneviratne, S.I., 2010. Energy balance closure of eddy-covariance data: A multisite analysis for European FLUXNET stations. Agric. For. Meteorol. 150, 1553-1567. doi:10.1016/j.agrformet.2010.08.005

- Graham, D. N., Butts, M.B., 2005. Flexible, integrated watershed modelling with MIKE SHE, In Watershed Models, Eds. V.P. Singh \& D.K. Frevert, 245-272, CRC Press. ISBN: 0849336090.

- Greve, M.H., Greve, M.B., Bøcher, P.K., Balstrøm, T., Breuning-Madsen, H., Krogh, L., 2007. Generating a Danish raster-based topsoil property map combining choropleth maps and point information. Geografisk Tidsskrift-Danish Journal of Geography 107, 1-12.

- Gryning, S.-E., Batchvarova, E., De Bruin, H.A.R., 2001. Energy balance of a sparse coniferous highlatitude forest under winter conditions. Bound.-Layer Meteor. 99, 465-488. 
- Göckede, M., Foken, T., Aubinet, M., Aurela, M., Banza, J., Bernhofer, C., Bonnefond, J.M., Brunet, Y., Carrara, A., Clement, R., Dellwik, E., Elbers, J., Eugster, W., Fuhrer, J., Granier, A., Grünwald, T., Heinesch, B., Janssens, I.A., Knohl, A., Koeble, R., Laurila, T., Longdoz, B., Manca, G., Marek, M., Markkanen, T., Mateus, J., Matteucci, G., Mauder, M., Migliavacca, M., Minerbi, S., Moncrieff, J., Montagnani, L., Moors, E., Ourcival, J.-M., Papale, D., Pereira, J., Pilegaard, K., Pita, G., Rambal, S., Rebmann, C., Rodrigues, A., Rotenberg, E., Sanz, M.J., Sedlak, P., Seufert, G., Siebicke, L., Soussana, J.F., Valentini, R., Vesala, T., Verbeeck, H., Yakir, D., 2008. Quality control of CarboEurope flux data Part 1: Coupling footprint analyses with flux data quality assessment to evaluate sites in forest ecosystems. Biogeosciences 5, 433-450. doi:10.5194/bg-5-433-2008

- Grimmond, C.S.B., Blackett, M., Best, M.J., Barlow, J., Baik, J.-J., Belcher, S.E., Bohnenstengel, S.I., Calmet, I., Chen, F., Dandou, A., Fortuniak, K., Gouvea, M.L., Hamdi, R., Hendry, M., Kawai, T., Kawamoto, Y., Kondo, H., Krayenhoff, E.S., Lee, S.-H., Loridan, T., Martilli, A., Masson, V., Miao, S., Oleson, K., Pigeon, G., Porson, A., Ryu, Y.-H., Salamanca, F., Shashua-Bar, L., Steeneveld, G.-J., Tombrou, M., Voogt, J., Young, D., Zhang, N., 2010. The International Urban Energy Balance Models Comparison Project: First Results from Phase 1. J. Appl. Meteorol. 49, 1268-1292. doi:10.1175/2010JAMC2354.1

- Gupta, H.V., Sorooshian, S., Yapo, P.O., 1998. Toward improved calibration of hydrologic models: Multiple and noncommensurable measures of information. Water Resour. Res. 34, 751-763. doi:10.1029/97WR03495

- Gupta, H.V., Bastidas, L.A., Sorooshian, S., Shuttleworth, W.J., Yang, Z.L., 1999. Parameter estimation of a land surface scheme using multicriteria methods. J. Geophys. Res. (1984-2012) 104, 19491-19503.

- Hansen, S., Jensen, H. E., Nielsen, N. E., Svendsen H., 1990. Daisy: Soil-plant-atmosphere system model. NPO National Agency of Environmental Protection Research Report No. A10. Copenhagen, Denmark.

- Hansen, S., Jensen, H. E., Nielsen, N. E., Svendsen H., 1991. Simulation of nitrogen dynamics and biomass production in winter wheat using the Danish simulation model DAISY. Fert. Res., 27, 245-259. 
- Hassan, Q.K., Bourque, C.P.-A., 2010. Spatial Enhancement of MODIS-based Images of Leaf Area Index: Application to the Boreal Forest Region of Northern Alberta, Canada. Remote Sens. 2, 278-289. doi:10.3390/rs2010278

- Hill, M.C., 1998. Methods and Guidelines for Effective Model Calibration. U.S. Geological Survey Water-Resources Investigations Report 98-4005, USA.

- Hou, Z., Huang, M., Leung, L. R., Lin, G., Ricciuto, D. M., 2012. Sensitivity of surface flux simulations to hydrologic parameters based on an uncertainty quantification framework applied to the Community Land Model, J. Geophys. Res., 117, D15108, doi:10.1029/2012JD017521.

- Hussein, A.S., 1999. Grass ET estimates using Penman-type equations in Central Sudan. J. Irrig. Drain. Eng. 125, 324-329.

- Højberg, A. L., Troldborg, L., Stisen, S., Christensen, B. B. S., Henriksen, H. J., 2013. Stakeholder driven update and improvement of a national water resources model, Environ. Modell. Softw., 40, 202213. doi:10.1016/j.envsoft.2012.09.010

- Ingwersen, J., Steffens, K., Högy, P., Warrach-Sagi, K., Zhunusbayeva, D., Poltoradnev, M., Gäbler, R., Wizemann, H.-D., Fangmeier, A., Wulfmeyer, V., Streck, T., 2011. Comparison of Noah simulations with eddy covariance and soil water measurements at a winter wheat stand. Agric. For. Meteorol. 151, 345355. doi:10.1016/j.agrformet.2010.11.010

- Iversen, B. V., Børgesen, C. D., Lægdsmand, M., Greve, M. H., Heckrath, G., Kjærgaard, C., 2011. Risk Predicting of Macropore Flow using Pedotransfer Functions, Textural Maps, and Modeling. Vadose Zone J., 10, 1185-1195, doi:10.2136/vzj2010.0140.

- Jensen, K.H., Illangasekare, T. H., 2011. HOBE: A Hydrological Observatory. Vadoze Zone J. 10, 1-7, doi:10.2136/vzj2011.0006.

- Kelliher, F.M., Leuning, R., Raupach, M.R., Schulze, E.-D., 1995. Maximum conductances for evaporation from global vegetation types. Agr. Forest. Meteorol.73, 1-16. doi:10.1016/01681923(94)02178-M 
- Lagergren, F., Eklundh, L., Grelle, A., Lundblad, M., Mölder, M., Lankreijer, H., Lindroth, A., 2005. Net primary production and light use efficiency in a mixed coniferous forest in Sweden. Plant, Cell \& Environ. 28, 412-423. doi:10.1111/j.1365-3040.2004.01280.x

- Lantinga, E.A., Nassiri, M., Kropff, M.J., 1999. Modelling and measuring vertical light absorption within grass-clover mixtures. Agr. Forest. Meteorol 96, 71-83.

- Larsen, M. A. D., Thejll, P., Christensen, J. H., Refsgaard, J. C., Jensen, K. H., 2013. On the role of domain size and resolution in the simulations with the HIRHAM region climate model, Clim Dyn 40, 2903-2918, doi:10.1007/s00382-012-1513-y.

- Larsen, M.A.D., Refsgaard, J.C., Drews, M., Butts, M.B., Jensen, K.H., Christensen, J.H., Christensen, O.B., 2014. Results from a full coupling of the HIRHAM regional climate model and the MIKE SHE hydrological model for a Danish catchment. Hydrol. Earth. Syst. Sc. 18, 4733-4749. doi:10.5194/hess$18-4733-2014$

- Lawrence, D.M., Oleson, K.W., Flanner, M.G., Thornton, P.E., Swenson, S.C., Lawrence, P.J., Zeng, X., Yang, Z.-L., Levis, S., Sakaguchi, K., Bonan, G.B., Slater, A.G., 2011. Parameterization improvements and functional and structural advances in Version 4 of the Community Land Model. J. Adv. Model. Earth Syst. 3, M03001. doi:10.1029/2011MS00045

- Lazzarotto, P., Calanca, P., Fuhrer, J., 2009. Dynamics of grass-clover mixtures-An analysis of the response to management with the PROductive GRASsland Simulator (PROGRASS). Ecol. Model. 220, 703-724. doi:10.1016/j.ecolmodel.2008.11.023

- Lazzarotto, P., Calanca, P., Semenov, M., Fuhrer, J., 2010. Transient responses to increasing CO2 and climate change in an unfertilized grass-clover sward. Clim. Res. 41, 221-232. doi:10.3354/cr00847

- Leuning, R., van Gorsel, E., Massman, W.J., Isaac, P.R., 2012. Reflections on the surface energy imbalance problem. Agric. For. Meteorol. 156, 65-74. doi:10.1016/j.agrformet.2011.12.002

- Li, H., Huang, M., Wigmosta, M.S., Ke, Y., Coleman, A.M., Leung, L.R., Wang, A., Ricciuto, D.M., 2011. Evaluating runoff simulations from the Community Land Model 4.0 using observations from flux towers and a mountainous watershed. J. Geophys. Res. 116, (D24120). doi:10.1029/2011JD016276 
- Lindroth, A., Lagergren, F., Aurela, M., Bjarnadottir, B., Christensen, T., Dellwik, E., Grelle, A., Ibrom, A., Johansson, T., Lankreijer, H., Launiainen, S., Laurila, T., MöLder, M., Nikinmaa, E., Pilegaard, K., Sigurdsson, B.D., Vesala, T., 2008. Leaf area index is the principal scaling parameter for both gross photosynthesis and ecosystem respiration of Northern deciduous and coniferous forests. Tellus B 60, 129-142. doi:10.1111/j.1600-0889.2007.00330.x

- Madsen, H., 2003. Parameter estimation in distributed hydrological catchment modelling using automatic calibration with multiple objectives. Adv. Water Resour. 26, 205-216.

- Mauder, M., Desjardins, R. L., Pattey, E., Gao, Z., van Haarlem, R., 2008. Measurement of the Sensible Eddy Heat Flux Based on Spatial Averaging of Continuous Ground-Based Observations. Bound.-Layer Meteorol. 128, 151-172. doi:10.1007/s10546-008-9279-9

- Maurer, E.P., Wood, A.W., Adam, J.C., Lettenmaier, D.P., Nijssen, B., 2002. A long-term hydrologically based dataset of land surface fluxes and states for the conterminous United States. J. Climate 15, 32373251.

- Mauser, W., Schädlich, S., 1998. Modelling the spatial distribution of evapotranspiration on different scales using remote sensing data. J. Hydrol. 212, 250-267.

- Maxwell, R.M., Lundquist, J.K., Mirocha, J.D., Smith, S.G., Woodward, C.S., Tompson, A.F.B., 2011. Development of a Coupled Groundwater-Atmosphere Model. Mon. Weather Rev. 139, 96-116. doi:10.1175/2010MWR3392.1

- Mertens, J., Madsen, H., Feyen, L., Jacques, D., Feyen, J., 2004. Including prior information in the estimation of effective soil parameters in unsaturated zone modelling. J. Hydrol., 294, 251-269, doi:10.1016/j.jhydrol.2004.02.011.

- Mertens, J., Madsen, H., Kristensen, M., Jacques, D., Feyen, J., 2005. Sensitivity of soil parameters in unsaturated zone modelling and the relation between effective, laboratory and in situ estimates, Hydrol. Process., 19, 1611-1633, doi:10.1002/hyp.5591. 
- Meyer, P. D., Rockhold, M. L., Wee, G. W., 1997. Uncertainty analyses of infiltration and subsurface flow and transport for SDMP sites. Division of Regulatory Applications Office of Nuclear Regulatory Research, U.S. Nuclear Regulatory Commission, Washington, USA.

- Moore, C., Doherty, J., 2005. Role of the calibration process in reducing model predictive error. Water Resour. Res. 41, W05020. doi:10.1029/2004WR003501

- Nghi, V. V., Dung, D. D., Lam, D. T., 2008. Potential evapotranspiration estimation and its effect on hydrological model response at the Nong Son Basin, VNU Journal of Science, Earth Sciences, 24, 213 223.

- Olesen, J.E., Berntsen, J., Hansen, E.M., Petersen, B.M., Petersen, J., 2002. Crop nitrogen demand and canopy area expansion in winter wheat during vegetative growth. Eur. J. Agron. 16, 279-294. doi:10.1016/S1161-0301(01)00134-4

- Olesen, J.E., Hansen, P.K., Berntsen, J., Christensen, S., 2004. Simulation of above-ground suppression of competing species and competition tolerance in winter wheat varieties. Field Crop. Res. 89, 263-280. doi:10.1016/j.fcr.2004.02.005

- Overgaard, J., 2005. Energy-based land-surface modelling: new opportunities in integrated hydrological modeling, Ph.D. Thesis, Institute of Environment and Resources, DTU, Technical University of Denmark.

- Perry, D. A., 1994. Forest Ecosystems. The Johns Hopkins University Press, Maryland. 1. Ed. ISBN 08018-4760-5.

- Pollacco, J.A.P., Mohanty, B.P., Efstratiadis, A., 2013. Weighted objective function selector algorithm for parameter estimation of SVAT models with remote sensing data: Parameter Estimation for Svat Model. Water Resour. Res. 49, 6959-6978. doi:10.1002/wrcr.20554

- Pokorný, R., Tomášková, I., Havránková, K., 2008. Temporal variation and efficiency of leaf area index in young mountain Norway spruce stand. Eur. J. For. Res. 127, 359-367. doi:10.1007/s10342-008-0212Z 
- Rautiainen, M., Heiskanen, J., Korhonen, L., 2012. Seasonal changes in canopy leaf area index and MODIS vegetation products for a boreal forest site in central Finland, Boreal Environ. Res., 17, 72-84.

- $\quad$ Ridler, M.E., Sandholt, I., Butts, M., Lerer, S., Mougin, E., Timouk, F., Kergoat, L., Madsen, H., 2012. Calibrating a soil-vegetation-atmosphere transfer model with remote sensing estimates of surface temperature and soil surface moisture in a semi arid environment. J. Hydrol. 436-437, 1-12. doi:10.1016/j.jhydrol.2012.01.047

- Ringgaard, R., 2012. On variability of evapotranspiration - The role of surface type and vegetation. Ph.D. Thesis, University Of Copenhagen, Department Of Geography and Geology, Denmark.

- $\quad$ Rosero, E., Yang, Z.-L., Wagener, T., Gulden, L.E., Yatheendradas, S., Niu, G.-Y., 2010. Quantifying land surface model over transition zones during the warm season. J. Geophys. Res. 115, D03106. doi:10.1029/2009JD012035

- Sahoo, G.B., Ray, C., De Carlo, E.H., 2006. Calibration and validation of a physically distributed hydrological model, MIKE SHE, to predict streamflow at high frequency in a flashy mountainous Hawaii stream. J. Hydrol. 327, 94-109. doi:10.1016/j.jhydrol.2005.11.012

- Schelde, K., Ringgaard, R., Herbst, M., Thomsen, A., Friborg, T. and Søgaard, H., 2011. Comparing Evapotranspiration rates estimated from Atmospheric Flux and TDR Soil Moisture Measurements, Vadose Zone J., 10, 78-83, doi:10.2136/vzj2010.0060.

- Schulze, E.-D., Kelliher, F.M., Korner, C., Lloyd, J., Leuning, R., 1994. Relationships among maximum stomatal conductance, ecosystem surface conductance, carbon assimilation rate, and plant nitrogen nutrition: a global ecology scaling exercise. . Annu. Rev. Ecol. Syst. 629-660. doi: 10.1146/annurev.es.25.110194.003213.

- Shrestha, P., Sulis, M., Masbou, M., Kollet, S., Simmer, C., 2014. A Scale-Consistent Terrestrial Systems Modeling Platform Based on COSMO, CLM, and ParFlow. Mon. Weather Rev. 142, 3466-3483. doi:10.1175/MWR-D-14-00029.1 
- Shuttleworth, W.J., Wallace, J.S., 1985. Evaporation from sparse crops-an energy combination theory. Q.J.R. Meteorol. Soc. 111, 839-855. doi:10.1002/qj.49711146910

- Sonnenborg, T. O., Pang, B., Bruge, A., Christiansen, J. R., Stisen, S., Gundersen, P., 2013. Modeling of evapotranspiration and groundwater recharge from forest. TR32-HOBE symposium, Bonn, Germany.

- Stisen, S., McCabe, M.F., Refsgaard, J.C., Lerer, S., Butts, M.B., 2011a. Model parameter analysis using remotely sensed pattern information in a multi-constraint framework. J. Hydrol. 409, 337-349. doi:10.1016/j.jhydrol.2011.08.030

- Stisen, S., Sonnenborg, T.O., Højberg, A.L., Troldborg, L., Refsgaard, J.C., 2011b. Evaluation of Climate Input Biases and Water Balance Issues Using a Coupled Surface-Subsurface Model. Vadose Zone J. 10, 37. doi:10.2136/vzj2010.0001

- Stisen, S., Højberg, A. L., Troldborg, L., Refsgaard, J. C., Christensen, B. B. S., Olsen, M., Henriksen, H. J., 2012. On the importance of appropriate precipitation gauge catch correction for hydrological modelling at mid to high latitudes. Hydrol. Earth Syst. Sc., 16, 4157-4176, doi:10.5194/hess-16-41572012.

- Stoy, P. C., Mauder, M., Foken, T., Marcolla, B., Boegh, E., Ibrom, A., Arain, M.A., Arneth, A., Aurela, M., Bernhofer, C., others, 2013. A data-driven analysis of energy balance closure across FLUXNET research sites: The role of landscape scale heterogeneity. Agric. For. Meteorol.171, 137-152.

- Styczen, M., Hansen, S., Jensen, L. S., Svendsen, H., Abrahamsen, P., Børgesen, C. D., Thirup, C., Østergaard, H. S., 2004a. Standardopstillinger til Daisy-modellen. Vejledning og baggrund. Version 1.2, april 2006. DHI Institut for Vand og Miljø, Denmark.

- Styczen, M., Hansen, S., Jensen, L. S., Svendsen, H., Abrahamsen, P., Børgesen, C. D., Thirup, C., Østergaard, H. S., 2004b. Appendix-samling, DHI Institut for Vand og Miljø, Denmark.

- Sun, G., Noormets, A., Chen, J., McNulty, S. G., 2008. Evapotranspiration estimates from eddy covariance towers and hydrologic modeling in managed forests in Northern Wisconsin, USA, Agr. Forest. Meteorol., 148, 257-267, doi:10.1016/j.agrformet.2007.08.010. 
- Sun, Y., Hou, Z., Huang, M., Tian, F., Ruby Leung, L., 2013. Inverse modeling of hydrologic parameters using surface flux and runoff observations in the Community Land Model. Hydrol. Earth. Syst. Sc. 17, 4995-5011. doi:10.5194/hess-17-4995-2013

- Thompson, J.R., Sørenson, H.R., Gavin, H., Refsgaard, A., 2004. Application of the coupled MIKE SHE/MIKE 11 modelling system to a lowland wet grassland in southeast England. J. Hydrol. 293, 151179. doi:10.1016/j.jhydrol.2004.01.017

- Topping, C., Olsen, J., 2006. Vegetation growth simulation in ALMaSS. Danish Ministry of the Environment report: Ukrudtsstriglingens effekter på dyr planter og ressourceforbrug, Appendix B, Danish Ministry of the Environment, Copenhagen, Denmark.

- Twine, T.E., Kustas, W.P., Norman, J.M., Cook, D.R., Houser, Pr., Meyers, T.P., Prueger, J.H., Starks, P.J., Wesely, M.L., 2000. Correcting eddy-covariance flux underestimates over a grassland. Agric. For. Meteorol. 103, 279-300.

- van Genuchten, M. Th., 1980. A closed-form equation for predicting the hydraulic conductivity of unsaturated soils, Soil Sci. Soc. Am. J., 44, 892-898. doi:10.2136/sssaj1980.03615995004400050002x.

- Van der Keur, P., Hansen, S., Schelde, K., Thomsen, A., 2001. Modification of DAISY SVAT model for potential use of remotely sensed data. Agric. For. Meteorol. 106, 215-231.

- Wang, Q., Tenhunen, J., Falge, E., Bernhofer, C.H., Granier, A., Vesala, T., 2004. Simulation and scaling of temporal variation in gross primary production for coniferous and deciduous temperate forests. Glob. Change Biol.10, 37-51. doi:10.1046/j.1529-8817.2003.00716.x.

- Wilson, K., Goldstein, A., Falge, E., Aubinet, M., Baldocchi, D., Berbigier, P., Bernhofer, C., Ceulemans, R., Dolman, H., Field, C., others, 2002. Energy balance closure at FLUXNET sites. Agric. For. Meteorol. $113,223-243$.

- Wösten, J. H. M., Lilly, A., Nemes, A., Le Bas, C., 1999. Development and use of a database of hydraulic properties of European soils, Geoderma, 90,169-185, doi:10.1016/S0016-7061(98)00132-3. 
- Xevi, E., Christiaens, K., Espino, A., Sewnandan, W., Mallants, D., Sørensen, H., Feyen, J., 1997. Calibration, validation and sensitivity analysis of the MIKE-SHE model using the Neuenkirchen catchment as case study. Water Resour. Manag.11, 219-242.

- Zhou, M.C., Ishidaira, H., Hapuarachchi, H.P., Magome, J., Kiem, A.S., Takeuchi, K., 2006. Estimating potential evapotranspiration using Shuttleworth-Wallace model and NOAA-AVHRR NDVI data to feed a distributed hydrological model over the Mekong River basin. J. Hydrol. 327, 151-173. doi:10.1016/j.jhydrol.2005.11.013

- Zweifel, R., Böhm, J.P., Häsler, R., 2002. Midday stomatal closure in Norway spruce-reactions in the upper and lower crown. Tree Physiol 22, 1125-1136.

Figure 1. Skjern catchment (Denmark). Locations of the flux tower and discharge sites and land use map (land use map from Jensen and Illangasekare (2011)).

Figure 2. Flow chart of the calibration process.

Figure 3. Measured radiation and energy flux components at the three Skjern catchment sites for the years 2009 and 2010, simulated components by the HIRHAM regional climate model, and measurements for year 2009 from an agricultural research station in Foulum located approx. $50 \mathrm{~km}$ north of the agriculture and forest sites. Yearly average values for each radiation and energy flux component is given in the legend. Measurements from the agricultural station in 2009 are bracketed due to extensive gap filling in this period.

Figure 4. Results of the sensitivity analyses for the individual sites and the distributed setup. For the distributed setup only the 20 most sensitive parameters are shown. The y-axis represents relative sensitivity in relation to the most sensitive parameter. 
Figure 5. Observed and simulated daily and accumulated discharge at three gauging stations based on two energy balance hypothesis setups for the calibration and validation periods.

Figure 6. Catchment scale simulation statistics. Root mean square error (RMSE) and mean absolute error (MAE) statistics for discharge, latent heat flux (LE) and sensible heat flux (H) for the two energy balance hypotheses and for both the calibration and validation period (RMSE only).

Figure 7. Example of model simulated LE and H energy fluxes for the distributed case and for the two energy balance hypotheses in the calibration period. Un-scaled and scaled observations are also shown. The data represent a summer period June 1-11, 2010 with cloudless conditions from June 15 and varying global radiation from June 6-11. Lines of the same colour are comparable.

Figure 8. Daily values for plant transpiration and soil evaporation as a function of the average root zone water content at the three sites in the calibration period for HYP2 and the corresponding soil field capacity ( $\mathrm{pF}$ 2) and saturation levels (dotted lines). 
Table 1. Point scale parameterization.

Initial parameter values, parameter range for the sensitivity and optimization analyses for the three sites, and the resulting range for the four energy balance hypotheses. A selection of literature used to provide initial and range of parameter values (primary references listed first next to each parameter): 1) Lagergren et al. (2005), 2) Boulet et al. (1999), 3) Bøgh et al. (2009), 4) Chen and Dudhia (2001a), 5) Rautiainen et al. (2012), 6) Crow (2005), 7) Gryning et al. (2001), 8) Lindroth et al. (2008), 9) Van der Keur et al. (2001), 10) Overgaard (2005), 11) Perry (1994), 12) Hansen et al. (1991), 13) Hussein (1999), 14) Lazzarotto et al. (2010), 15) Topping and Olesen (2006), 16) Nghi et al. (2008), 17), Olesen et al. (2002), 18), Olesen et al. (2004), 19) Beier et al. (1995), 20) Bréda (2003), 21) Hassan and Borque (2010), 22) Pokorný et al. (2008), 23) Stisen et al. (2011a), 24) Lantinga et al. (1999), 25) Zweifel et al. (2002), 26) Lazzarotto et al. (2009), 27) Ingwersen et al. (2011), 28) Kelliher et al. (1995), 29) Zhou et al. (2006), 30) Wang et al. (2003), 31) Ridler et al. (2012), 32) Sahoo et al. (2006), 33), Xevi et al (1997), 34) Dai et al. (2010), 35) Ewers et al. (2001), 36) Frank et al. (1996), 37) Schulze et al. (1994) and 38) Stisen et al. (2011b).

* Seasonal variation included. If brackets only some of the sites include seasonality (A; agriculture, M; meadow). With seasonality, the values are from mid-summer.

${ }^{S}$ Parameter only included only in the sensitivity analysis.

Initial parameter value based on ${ }^{\mathrm{O}}$ observations, ${ }^{\mathrm{SIM}}$ simulated values by Daisy model and ${ }^{\mathrm{VG}}$ Van Genuchten parameter derived from pedotransfer function. Parameter values are considered for the A, B and C horizons and the parameter ranges are derived from Meyer et al (1997). 


\begin{tabular}{|c|c|c|c|c|c|c|c|c|c|}
\hline & Agriculture & & & Forest & & & Meadow & & \\
\hline Parameter & Initial value & $\begin{array}{l}\text { Rang } \\
\text { e }\end{array}$ & $\begin{array}{l}\text { Calibrate } \\
\text { d values } \\
\text { (hypothes } \\
\text { is range) }\end{array}$ & Initial value & $\begin{array}{l}\text { Rang } \\
\text { e }\end{array}$ & $\begin{array}{l}\text { Calibrated } \\
\text { values } \\
\text { (hypothesis } \\
\text { range) }\end{array}$ & Initial value & $\begin{array}{l}\text { Rang } \\
\text { e }\end{array}$ & $\begin{array}{l}\text { Calibrated } \\
\text { values } \\
\text { (hypothesis } \\
\text { range) }\end{array}$ \\
\hline $\begin{array}{l}\text { Leaf area } \\
\text { index* } \\
\left(\mathrm{m}^{2} / \mathrm{m}^{2}\right)\end{array}$ & $\begin{array}{l}4.6 \\
(\mathrm{SIM}, 9,29,37,27, \\
15)\end{array}$ & $\begin{array}{l}2.56- \\
6.64\end{array}$ & $2.69-3.35$ & $\begin{array}{l}4.8 \\
(O, 19,1,5,29,37,20,3,7,8,16,21,2 \\
2,30)\end{array}$ & $\begin{array}{l}3.6- \\
10.2\end{array}$ & $3.15-7.07$ & $4.5(15,26,29,37)$ & $\begin{array}{l}2.5- \\
6.66\end{array}$ & $2.74-3.08$ \\
\hline $\begin{array}{l}\text { Root } \\
\operatorname{depth} *(A, \\
\text { M) }(\mathbf{m})\end{array}$ & $0.78($ SIM, 29$)$ & $\begin{array}{l}0.2- \\
0.8\end{array}$ & - & $1.5(6,29,3)$ & $1-2$ & $1.29-1.95$ & $0.6(\operatorname{SIM}, 3,29)$ & $\begin{array}{l}0.4- \\
0.8\end{array}$ & - \\
\hline $\begin{array}{l}\text { Minimum } \\
\text { stomatal } \\
\text { resistance } \\
\text { (Rst_min) } \\
\text { (s/m) }\end{array}$ & $\begin{array}{l}90 \\
(9,28,29,37,23,27 \\
, 4)\end{array}$ & $\begin{array}{l}50- \\
200\end{array}$ & $100-194$ & $125(23,28,25,29,35,37,4,16)$ & $\begin{array}{l}65- \\
258\end{array}$ & $188-236$ & $\begin{array}{l}92.5 \\
(2,28,29,36,37,23 \\
, 4)\end{array}$ & $\begin{array}{l}55- \\
250\end{array}$ & $212-241$ \\
\hline $\begin{array}{l}\text { Extinction } \\
\text { coefficient }\end{array}$ & $\begin{array}{l}0.53 \\
(23,17,18,15,12)\end{array}$ & $\begin{array}{l}0.4- \\
0.85\end{array}$ & $0.47-0.66$ & $0.46(1,23,20,11)$ & $\begin{array}{l}0.15- \\
0.52\end{array}$ & - & $\begin{array}{l}0.45 \\
(15,26,23,14,13,2 \\
4)\end{array}$ & $\begin{array}{l}0.25- \\
0.75\end{array}$ & $0.26-0.45$ \\
\hline $\begin{array}{l}\text { Leaf width } \\
\text { (m) }\end{array}$ & $0.01(9,29)$ & $\begin{array}{l}0.005- \\
0.3\end{array}$ & $0.05-0.26$ & $0.0025(29)$ & $\begin{array}{l}0.000 \\
5-0.3\end{array}$ & $0.01-0.05$ & $0.01(9,29)$ & $\begin{array}{l}0.005- \\
0.3\end{array}$ & $0.01-0.03$ \\
\hline $\begin{array}{l}\text { Vegetation } \\
\text { height* }(\mathrm{A} \text {, } \\
\text { M) }(\mathbf{m})\end{array}$ & 0.78 (SIM) & $\begin{array}{l}0.51- \\
1.03\end{array}$ & $0.55-0.98$ & $17.5(\mathrm{O}, 3)$ & $\begin{array}{l}10- \\
22.5\end{array}$ & $11.1-19.8$ & $0.3(3)$ & $\begin{array}{l}0.11- \\
0.49\end{array}$ & $0.04-0.08$ \\
\hline $\begin{array}{l}\text { Roughness } \\
\text { length*(A, } \\
\text { M) (m) }\end{array}$ & $0.03(10,29,31)$ & $\begin{array}{l}0.007 \\
5-0.12\end{array}$ & - & $0.03(10,29,31)$ & $\begin{array}{l}0.007 \\
5-0.12\end{array}$ & - & $0.03(10,29,31)$ & $\begin{array}{l}0.007 \\
5-0.12\end{array}$ & - \\
\hline $\begin{array}{l}\text { Interceptio } \\
\mathbf{n} \\
\text { coefficient } \\
(\mathbf{m m})\end{array}$ & $\begin{array}{l}0.05 \\
(29,31,32,33,34)\end{array}$ & $\begin{array}{l}0.01- \\
0.2\end{array}$ & $0.02-0.13$ & $0.05(29,31,32,33,34)$ & $\begin{array}{l}0.01- \\
0.2\end{array}$ & $0.01-0.15$ & $\begin{array}{l}0.05 \\
(29,31,32,33,34)\end{array}$ & $\begin{array}{l}0.01- \\
0.2\end{array}$ & $0.05-0.16$ \\
\hline $\begin{array}{l}\text { Root shape } \\
\text { factor }\end{array}$ & $1(31,32,33)$ & $0.2-4$ & $0.24-3.66$ & $1(31,32,33)$ & $0.2-4$ & $0.02-0.07$ & $1(31,32,33)$ & $0.2-4$ & - \\
\hline $\begin{array}{l}\text { Detention } \\
\text { storage } \\
(\mathrm{mm})\end{array}$ & $10(34,38)$ & $5-100$ & - & 10 & $5-100$ & $11.5-46-5$ & 10 & $5-100$ & 49.4 \\
\hline $\begin{array}{l}\text { Initial } \\
\text { water } \\
\text { content } \\
\left(\mathbf{m}^{3} / \mathbf{m}^{3}\right)\end{array}$ & 0.2 & $\begin{array}{l}0.1- \\
0.4\end{array}$ & - & 0.2 & $\begin{array}{l}0.1- \\
0.4\end{array}$ & - & 0.2 & $\begin{array}{l}0.1- \\
0.4\end{array}$ & - \\
\hline $\begin{array}{l}\text { Van } \\
\text { Genuchten } \\
\alpha\left(\mathrm{cm}^{-1}\right)\end{array}$ & $\begin{array}{l}0.062 / 0.082 / 0.08 \\
5(\mathrm{VG})\end{array}$ & $\begin{array}{l}0.008 \\
7- \\
0.128\end{array}$ & $0.01-0.1$ & $0.062 / 0.082 / 0.085(\mathrm{VG})$ & $\begin{array}{l}0.008 \\
7- \\
0.128\end{array}$ & $0.01-0.02$ & $\begin{array}{l}0.048 / 0.058 / 0.05 \\
6(\mathrm{VG})\end{array}$ & $\begin{array}{l}0.004 \\
5-0.11\end{array}$ & - \\
\hline $\begin{array}{l}\text { Van } \\
\text { Genuchten } \\
\text { n }\end{array}$ & $\begin{array}{l}1.445 / 1.58 / 1.72 \\
(\mathrm{VG})\end{array}$ & $\begin{array}{l}1.25- \\
1.88\end{array}$ & - & 1.445/1.58/1.72(VG) & $\begin{array}{l}1.25- \\
1.88\end{array}$ & - & $\begin{array}{l}1.3 / 1.35 / 1.32 \\
(\mathrm{VG})\end{array}$ & $\begin{array}{l}1.16- \\
1.65\end{array}$ & $\mid 12.2-14.9$ \\
\hline $\begin{array}{l}\text { Saturated } \\
\text { hydraulic } \\
\text { conductivit } \\
\text { y }\left(\mathrm{m} \mathrm{s}^{-1}\right)\end{array}$ & $\begin{array}{l}1.4 \mathrm{E}-5 / 1.04 \mathrm{E}- \\
5 / 1.12 \mathrm{E}-5(\mathrm{VG})\end{array}$ & $\begin{array}{l}3.9 \mathrm{E}- \\
7- \\
1.86 \mathrm{E} \\
-4\end{array}$ & $\begin{array}{l}3.9 \mathrm{E}-7- \\
5.5 \mathrm{E}-7\end{array}$ & $1.4 \mathrm{E}-5 / 1.04 \mathrm{E}-5 / 1.12 \mathrm{E}-5(\mathrm{VG})$ & $\begin{array}{l}3.9 \mathrm{E}- \\
7- \\
1.86 \mathrm{E} \\
-4\end{array}$ & $\begin{array}{l}4 \mathrm{E}-7- \\
4.24 \mathrm{E}-7\end{array}$ & $6.86 \mathrm{E}-6(\mathrm{VG})$ & $\begin{array}{l}3.49 \mathrm{E} \\
-9- \\
1.34 \mathrm{E} \\
-4\end{array}$ & $\begin{array}{l}7.6 \mathrm{E}-7- \\
4.9 \mathrm{E}-6\end{array}$ \\
\hline $\begin{array}{l}\text { Residual } \\
\text { water }\end{array}$ & $\begin{array}{l}1.0 \mathrm{E}-3 / 1.0 \mathrm{E}- \\
3 / 1.0 \mathrm{E}-3(\mathrm{VG})\end{array}$ & $\begin{array}{l}0- \\
0.028\end{array}$ & - & $1.0 \mathrm{E}-3 / 1.0 \mathrm{E}-3 / 1.0 \mathrm{E}-3(\mathrm{VG})$ & $\begin{array}{l}0- \\
0.028\end{array}$ & - & $\begin{array}{l}0.02 / 0.02 / 0.02 \\
(\mathrm{VG})\end{array}$ & $\begin{array}{l}0.017- \\
0.11\end{array}$ & - \\
\hline
\end{tabular}

Comment [madla1]: We noticed that, by mistake, leaf width results had bee copied to here. 


\begin{tabular}{|c|c|c|c|c|c|c|c|c|c|}
\hline $\begin{array}{l}\text { content } \\
\left(\mathbf{m}^{3} / \mathbf{m}^{3}\right)\end{array}$ & & & & & & & & & \\
\hline $\begin{array}{l}\text { Saturated } \\
\text { water } \\
\text { content } \\
\left(\mathrm{m}^{3} / \mathrm{m}^{3}\right)\end{array}$ & $\begin{array}{l}0.40 / 0.38 / 0.35 \\
(\mathrm{VG})\end{array}$ & $\begin{array}{l}0.25- \\
0.54\end{array}$ & - & $0.40 / 0.38 / 0.35(\mathrm{VG})$ & $\begin{array}{l}0.25- \\
0.54\end{array}$ & & $\begin{array}{l}0.42 / 0.41 / 0.37 \\
\text { (VG) }\end{array}$ & $\begin{array}{l}0.40- \\
0.59\end{array}$ & - \\
\hline $\begin{array}{l}\text { Gr.water } \\
\text { table*, (M) } \\
\text { (m below } \\
\text { surface) }\end{array}$ & $5(\mathrm{O})$ & $2-10$ & - & $10(\mathrm{O})$ & $5-15$ & - & $0.25(\mathrm{O})$ & $0-0.5$ & - \\
\hline
\end{tabular}

Table 2. Catchment scale parameterization.

Initial parameter values and parameter ranges for the sensitivity and optimization analyses for the distributed calibration. Additional literature related to the distributed setup includes: 1) Chen and Dudhia (2001a), 2) Stisen et al. (2011b), 3) Thompson et al. (2004) and 4) Dai et al. (2010).

* Seasonal variation included. If brackets only some of the sites include seasonality (A; agriculture, M; meadow). With seasonality, the values are from mid-summer. 


\begin{tabular}{|c|c|c|c|c|c|c|}
\hline & & \multirow{3}{*}{$\begin{array}{l}\text { Range } \\
\text { HYP1 and HYP2 }\end{array}$} & \multirow{2}{*}{\multicolumn{2}{|c|}{ HYP1 }} & \multirow{2}{*}{\multicolumn{2}{|c|}{ HYP2 }} \\
\hline & & & & & & \\
\hline Parameter & Distribution type & & $\begin{array}{l}\text { Initial } \\
\text { value }\end{array}$ & $\begin{array}{l}\text { Calibrated } \\
\text { value }\end{array}$ & $\begin{array}{l}\text { Initial } \\
\text { value }\end{array}$ & $\begin{array}{l}\text { Calibrated } \\
\text { value }\end{array}$ \\
\hline Leaf area index* $\left(\mathrm{m}^{2} / \mathrm{m}^{2}\right)$ & \multirow[t]{7}{*}{ Agriculture } & $2.56-6.64$ & 2.97 & 5.66 & 2.69 & \multirow{7}{*}{0.23} \\
\hline Root depth*(A,M) (m) & & $0.2-0.8$ & 0.78 & & 0.78 & \\
\hline $\begin{array}{l}\text { minimum stomatal resistance (Rst_min) } \\
(\mathrm{s} / \mathbf{m})\end{array}$ & & $50-200$ & 136 & & 194 & \\
\hline Extinction coefficient & & $0.4-0.85$ & 0.66 & & 0.47 & \\
\hline Leaf width (m) & & $0.005-0.3$ & 0.05 & & 0.25 & \\
\hline Vegetation height* $(\mathrm{A}, \mathrm{M})(\mathrm{m})$ & & $0.51-1.03$ & 0.8 & & 0.98 & \\
\hline Roughness length*(A,M) (m) & & $0.05-0.13$ & $0.08(1)$ & & $0.098(1)$ & \\
\hline Leaf area index* $\left(\mathrm{m}^{2} / \mathrm{m}^{2}\right)$ & \multirow[t]{7}{*}{ Forest } & $3.6-10.2$ & 3.84 & 7.41 & 3.15 & 3.12 \\
\hline Root depth*(A,M) (m) & & $1-2$ & 1.95 & & 1.34 & \\
\hline $\begin{array}{l}\text { minimum stomatal resistance (Rst_min) } \\
(\mathrm{s} / \mathrm{m})\end{array}$ & & $65-258$ & 188 & 244 & 193 & 237 \\
\hline Extinction coefficient & & $0.15-0.52$ & 0.46 & 0.16 & 0.46 & 0.22 \\
\hline Leaf width (m) & & $0.0005-2$ & 0.04 & 1.93 & 1 & 0.85 \\
\hline Vegetation height*(A,M) (m) & & $10-22.5$ & 19.8 & 13.2 & 11.1 & 10.6 \\
\hline Roughness length*(A,M) (m) & & $1-2.25(1)$ & 0.2 & 0.014 & 0.11 & 0.04 \\
\hline Leaf area index* $\left(\mathrm{m}^{2} / \mathrm{m}^{2}\right)$ & \multirow[t]{7}{*}{ Meadow } & $2.5-6.66$ & 2.74 & & 2.73 & 3.95 \\
\hline Root depth*(A,M) (m) & & $0.4-0.8$ & 0.6 & & 0.6 & \\
\hline $\begin{array}{l}\text { minimum stomatal resistance (Rst_min) } \\
(\mathrm{s} / \mathbf{m})\end{array}$ & & $55-250$ & 247 & & 238 & \\
\hline Extinction coefficient & & $0.25-0.75$ & 0.26 & & 0.45 & \\
\hline Leaf width (m) & & $0.005-0.3$ & 0.02 & & 0.01 & 0.0085 \\
\hline Vegetation height* $(\mathrm{A}, \mathrm{M})(\mathrm{m})$ & & $0.11-0.49$ & 0.27 & & 0.15 & \\
\hline Roughness length $*(\mathrm{~A}, \mathrm{M})(\mathrm{m})$ & & $0.011-0.049(1)$ & 0.007 & & 0.004 & \\
\hline Interception coefficient (mm) & \multirow[t]{10}{*}{ Global } & $0.01-0.2$ & 0.13 & & 0.07 & 0.148 \\
\hline Root shape factor & & $0.2-4$ & 0.89 & 0.46 & 3.66 & 0.39 \\
\hline Detention storage & & $5-100$ & 40 & & 40 & 95 \\
\hline Night cloudiness & & $0.01-0.99$ & 0.5 & 0.0136 & 0.5 & \\
\hline Drainage time constant $\left(\mathrm{s}^{-1}\right)$ & & $6.50 \mathrm{E}-08-5.5 \mathrm{E}-7$ (4) & $1.02 \mathrm{E}-07$ & & $1.02 \mathrm{E}-07$ & \\
\hline Leakage coefficient $(\mathbf{m} / \mathbf{s})$ & & $1.38 \mathrm{E}-7-1.38 \mathrm{E}-5(2,3)$ & $1.38 \mathrm{E}-06$ & $1.17 \mathrm{E}-6$ & $1.38 \mathrm{E}-06$ & \\
\hline Overland Manning number $\left(\mathrm{m}^{1 / 2} \mathrm{~s}^{-1}\right)$ & & $2-15(2,3)$ & 7.5 & & 7.5 & \\
\hline River manning number $\left(\mathrm{m}^{1 / 2} \mathrm{~s}^{-1}\right)$ & & $18.75-31.25(3)$ & 25 & & 25 & \\
\hline Soil heat capacity reduction & & 0.01-0.99 & 0.5 & 0.48 & 0.5 & 0.13 \\
\hline Soil heat conductivity reduction & & $0.01-0.99$ & 0.5 & 0.0121 & 0.5 & 0.039 \\
\hline Van Genuchten $\alpha\left(\mathrm{cm}^{-1}\right)$ & \multirow[t]{5}{*}{$\begin{array}{l}\text { By soil type (values } \\
\text { for top layer) }\end{array}$} & $0.009-0.128$ & 0.0129 & 0.093 & 0.126 & \\
\hline Van Genuchten n & & $1.2459-1.8842$ & 1.27 & 1.7 & 1.3 & 1.51 \\
\hline $\begin{array}{l}\text { Saturated hydraulic conductivity (K_sat) } \\
\left(\mathrm{m} \mathrm{s}^{-1}\right)\end{array}$ & & $3.9 \mathrm{E}-7-1.86 \mathrm{E}-4$ & $1.40 \mathrm{E}-05$ & $1.01 \mathrm{E}-5$ & $4.00 \mathrm{E}-07$ & $2.02 \mathrm{E}-6$ \\
\hline Residual water content (m3/m3) & & $0-0.0278$ & 0 & & 0 & \\
\hline Saturated water content $(\mathrm{m} 3 / \mathrm{m} 3)$ & & $0.247-0.543$ & 0.53 & & 0.537 & \\
\hline
\end{tabular}


Table 3. Catchment scale simulation water balance. Water balance components for the total catchment as well as values from the grid cells of the three flux tower sites extracted from the distributed catchment. The total catchment albedos are area weighted values and the observed ET values are in brackets.

\begin{tabular}{|c|c|c|c|c|c|c|c|c|}
\hline & \multicolumn{2}{|c|}{ Total catchment } & \multicolumn{2}{|l|}{ Agri. } & \multicolumn{2}{|l|}{ Forest } & \multicolumn{2}{|l|}{ Meadow } \\
\hline & HYP1 & HYP2 & HYP1 & HYP2 & HYP1 & HYP2 & HYP1 & HYP2 \\
\hline \begin{tabular}{|l|} 
Albedo \\
\end{tabular} & 0.18 & 0.35 & 0.19 & 0.32 & 0.08 & 0.40 & 0.19 & 0.42 \\
\hline Precipitation (mm) & 1094 & 1094 & 1119 & 1119 & 1007 & 1007 & 991 & 991 \\
\hline Evapotranspiration (mm) & 481 & 454 & 424 (407) & $434(407)$ & $561(519)$ & $460(519)$ & $584(440)$ & $539(440)$ \\
\hline Canopy Evap. (mm) & 192 & 133 & 165 & 83 & 278 & 118 & 245 & 260 \\
\hline Recharge (mm) & 513 & 579 & 708 & 700 & 151 & 383 & 412 & 468 \\
\hline Discharge $(\mathrm{mm})$ & 412 & 453 & 0 & 0 & 0 & 0 & 366 & 420 \\
\hline Overland flow (mm) & 11 & 11 & 0 & 0 & 0 & 0 & 0 & 0 \\
\hline Pumping (mm) & 55 & 50 & 104 & 104 & 0 & 0 & 0 & 0 \\
\hline Baseflow to river (mm) & 205 & 216 & 0 & 0 & 0 & 0 & 43 & 40 \\
\hline Drain to river $(\mathrm{mm})$ & 207 & 237 & 30 & 164 & 0 & 0 & 323 & 380 \\
\hline
\end{tabular}




\section{Calibration of a distributed hydrology and land surface model using energy flux}

\section{2 measurements}

4 Morten A. D. Larsen ${ }^{1 *}$, Jens C. Refsgaard ${ }^{2}$, Karsten H. Jensen ${ }^{3}$, Michael B. Butts ${ }^{4}$, Simon Stisen $^{2}$ and Mikkel Mollerup ${ }^{5}$. 5

61 - Technical University of Denmark, Department of Management Engineering, Frederiksborgvej 399, 4000 Roskilde,

7 Denmark

82 - Geological Survey of Denmark and Greenland, Øster Voldgade 10, 1350 Copenhagen, Denmark.

93 - University of Copenhagen, Department of Geosciences and Natural Resource Management, Øster Voldgade 10,

101350 Copenhagen, Denmark.

114 - DHI, Agern Alle 5, DK 2970, Hørsholm, Denmark

125 - The Danish Road Directorate, Guldalderen 12, 2640 Hedehusene.

13 * - Corresponding author: madla@dtu.dk/004525119895

14

Keywords: hydrology/land surface modelling; calibration; water and energy fluxes;

evapotranspiration; energy closure imbalance

\section{Abstract}

In this study we develop and test a calibration approach on a spatially distributed groundwater-surface water catchment model (MIKE SHE) coupled to a land surface model component with particular focus on the water and energy fluxes. The model is calibrated against time series of eddy flux measurements from three sites of different land surface type (agriculture, forest and meadow) and river discharge data from the $2500 \mathrm{~km}^{2}$ Skjern River catchment in Denmark. The approach includes initial calibrations of three one-dimensional models representing the three land surface types and-using the flux measurements for calibration. This step provides 
initial values for the subsequent modelling and calibration at catchment scale. To test the validity of the approach, two additional catchment scale distributed simulations were performed with no calibration and only calibration of the one-dimensional models, respectively. In addition, a subsequent validation period was simulated. A mean energy closure imbalance of $20 \%$ was seen for the three sites. For the distributed simulations, the energy imbalance was accounted for by two energy balance closure hypotheses ascribing the error to either energy fluxes or net radiation. In general, the distributed calibration approach improved model results substantially compared to using default values (no calibration) or calibration of the one-dimensional models only. For the distributed model simulations, the assumption regarding the energy balance closure had a substantial impact on the parameter sensitivities and on the simulated discharge and energy balance. During calibration, the simulation with corrected energy fluxes showed better performance on discharge than the simulation with corrected net radiation whereas the reverse was true for the validation period. Regarding energy fluxes, the simulation with corrected net radiation was superior in both the calibration and validation period.

\section{Introduction}

Water and energy fluxes between land surface and atmosphere are important components of atmospheric and hydrological processes. These fluxes can be quantified by the use of land surface models (LSM) or soil-vegetation-atmosphere-transfer models (SVAT). The calculation of e.g. evapotranspiration in SVATs and LSMs is based on solving the energy and radiation equations often on a sub-daily basis and they therefore differ from the less physically stringent schemes often used in many traditional hydrological models which are based on potential evapotranspiration. LSMs, originating from atmospheric sciences, include spatially distributed, often large scale descriptions of land surface processes. Examples include the Noah model (Rosero et al. 2010) and the CLM model 
(Lawrence et al. 2011). LSMs are typically coupled with or forced by atmospheric models and have recently been included in fully coupled climate-hydrology models (Maxwell et al. 2011, Shrestra et al. 2014). SVATs, originating from soil and hydrological sciences, are one-dimensional descriptions typically used for small-scale descriptions linked with soil water flow models (Mauser and Schädlich 1998, Ridler et al. 2012). When included in spatially distributed hydrological models they possess the potential for providing improved evapotranspiration descriptions and enable hydrological catchment models to better utilise remote sensing data to force and constrain hydrological models (Stisen et al. 2011a). SVATs have also recently been included in fully coupled climate-hydrology models (Butts et al. 2014, Larsen et al. 2014). LSMs and SVATs linked to spatially distributed hydrological models are basically similar, and hence we shall in the following refer to both of them as SVAT models.

Assessment of parameter values is critical for the use of SVAT models and an essential challenge is related the vast number of parameters often seen in this type of models. Franks et al. (1997, 1999), Beven and Franks (1999) and Gupta et al. (1999) all highlight the high uncertainty in the predictive capabilities of multi-parameter SVATs due to equifinality. Yet; Franks et al. (1997, 1999) still show good results in terms of reproducing point site flux measurements from the FIFE area in Kansas, USA, and in the Amazon area in Brazil. The added value of a multi-criteria approach as opposed to a single criterion method is confirmed by Gupta et al. (1999) and Demarty et al. (2004). Pollacco et al. (2013) apply an objective function weighing algorithm based on the Parameter estimation for hydrological models is traditionally performed by use of calibration where parameter values are modified to obtain best possible fit between model 
simulations and observed target data. While calibration was previously often performed manually by a trial-and-error approach, parameter optimisation by inverse modelling is now the method of choice (Gupta et al. 1998, Madsen 2003, Moore and Doherty 2005). An example is the study by Sun et al. (2013) where inverse calibration based on Monte Carlo-Bayesian techniques was used for calibrating a model both against energy fluxes at point scale and runoff at catchment scale (4.9 $\mathrm{km}^{2}$ ). In Ingwersen et al. (2011) inverse calibration was used to simulate the water and energy budget for a winter wheat stand at plot scale. Similarly Ridler et al. (2012) utilized inverse techniques for calibrating the combined MIKE SHE/SWET model to simulate energy fluxes at point scale in Mali.

A particular problem related to calibration of SVAT models is that observations of water and energy fluxes are usually not available from operational monitoring networks but only from a few research stations and often for short periods (Wilson et al. 2002, Franssen et al. 2010, Leuning et al. 2012). In addition, energy flux data are known to often have problems with energy balance closure which severely hampers parameter optimisation by inverse modelling, as a SVAT model per definition assumes a closed energy balance (Twine et al. 2000, Choi et al. 2009) and a failure to meet this demand can result in significant biases in long term climate model simulations (Grimmond et al. 2010). Also, the lack of measured energy balance closure will yield an erroneous parameterization when the fluxes are used for the calibration of a hydrological model. Therefore certain assumptions need to be made to account for the lack of closure. To accommodate this, Beven (2006) suggested creating artificial hypotheses to provide closure.

Catchment water balances are linked to energy balances, because the latent energy/evapotranspiration appears as a key element in both balances. The observed catchment runoff and the catchment water balance assessed by hydrological models hence include important information also on the energy balance. On a catchment scale $\left(603 \mathrm{~km}^{2}\right)$ Barr et al. (2012) used 
distributed flux tower measurements of evapotranspiration against measured precipitation and $\underline{\text { discharge for a residual analysis on water balance closure concluding a } 15 \% \text { lack of energy flux }}$ closure compared to the measured net energy. For catchment scale $\left(205 \mathrm{~km}^{2}\right)$ model calibration, $\mathrm{Li}$ et al. (2011) used both runoff and energy fluxes for model calibration. Thethe CLM4 model-was, modified to include a runoff scheme-and-calibration for a $205 \mathrm{~km}^{2}$-catchment was performed manually against, to evaluate both runoff and at the same time considering energy fluxes. Similarly, operating on a regional to continental scale Maurer et al. (2002) simulated energy flux components while the model was manually calibrated only against runoff.

The objectives of the present study is to develop and test a methodology for calibrating and assessing parameters of a SVAT model linked to a spatially distributed hydrological model by using observations of both energy fluxes and catchment runoff. A comprehensive literature study was carried out to obtain feasible initial values and range of variation for parameters for the considered land surface types. The impact of energy imbalance is of particular emphasis and we analyse to which extent inclusion of discharge observations in the calibration process will improve the model performance and robustness.

\section{Methodology}

\subsection{Study area and data}

The Skjern catchment $\left(2500 \mathrm{~km}^{2}\right)$ is located in the western part of the Jutland peninsula, Figure 1 . The catchment is dominated by sandy soils generated by glacial outwash plains from the last glacial period Weichsel and intersected by older till deposits from the previous glacial period Saalian (Greve et al. 2007). The topography reaches $130 \mathrm{~m}$ above sea level in the eastern part of the catchment and the Skjern River flow into Ringkøbing fjord at sea level to the west. The yearly average precipitation for the catchment is $940 \mathrm{~mm}$ for the period 2000-2009 based on direct 
measurements. When corrected for undercatch using standard monthly correction factors (Allerup et al. 1998) the average precipitation amounts to $1130 \mathrm{~mm}$. In the same period the mean annual temperature is $9.3{ }^{\circ} \mathrm{C}$ and the mean monthly temperatures range between 2.1 and $17.3{ }^{\circ} \mathrm{C}$. Inside the catchment flux towers are placed at the three predominant surface types; agriculture (61\%), meadow/grass (24\%) and forest (13\%), Figure 1. At all sites measurements of short-, long-wave and net radiation components; latent $(\mathrm{LE})$, sensible $(\mathrm{H})$ and soil heat fluxes $(\mathrm{G})$; soil water content; precipitation; air temperature; wind speed; and water table levels have been carried out since late 2008. Measurements of radiation and energy fluxes are based on standard methods. Radiation components are measured using a NR01 Hukseflux radiometer (www.hukseflux.com), LI-COR

131 eddy covariance equipment is used for measuring LE fluxes, Gill sonic anemometers for measuring 132 H fluxes, and Hukseflux plates for measuring G fluxes. The energy flux data used in the study have undergone quality control as part of the 134 processing (Ringgard, 2012) (Step 1.3, Figure 2). Inaccurate observations caused by e.g. low 135 turbulence condition were replaced by data representing similar conditions. Replacement of data 136 was thus for periods with low energy fluxes and therefore this source of uncertainty is expected to 137 be of minor significance. Individual data points clearly outside the expected range at the time of day 138 and season were considered as outliers and removed-(equal to $0.2 \%$ on average between LE, $\mathrm{H}$ and 139 the three stations weighted relative the areal share). For two periods July 21-August 16 and August 140 24-October 28, 2009, no flux measurements were available from the agricultural site and data were 141 replaced from the forest site. As these periods are mostly placed in the spin-up period (see below) 142 the calibration results are not expected to be significantly affected. 
This study uses the spatially distributed MIKE SHE hydrological modelling system capable 146 of including all key hydrological processes such as ET, channel flow, overland flow, unsaturated 147 flow, saturated flow as well as irrigation and drainage (Graham and Butts 2005). The land surface model SWET component (Overgaard, 2005) is used in the analysis. SWET is based on the 149 Shuttleworth-Wallace model (Shuttleworth and Wallace 1985). It considers vegetation and energy 150 balance processes in a two-layer system and is extended to include energy fluxes from ponded 151 water and interception storage. Models are constructed for both the three local measurement sites (1D representation) and for the entire catchment (Figure 1).

The 1D models simulate energy fluxes and vertical unsaturated flow based on Richards' equation. The SWET model is driven by $30 \mathrm{~min}$ climatic observations of precipitation, air temperature, wind speed, net radiation, surface air pressure and relative humidity. Measured water table elevations are specified as lower boundary condition. As opposed to the fully distributed model application overland flow, river flow and groundwater flow are not considered. Relevant to both the 1D and distributed analyses, the SWET land-surface module does not consider snow accumulation and melting. Initial values for root depth and vegetation height applicable for the 1D

160 simulations of the agricultural and meadow sites were based on estimates from model simulations 161 for relevant soil type and management conditions using the vegetation model Daisy (Styczen et al. 162 2004a). Since the footprint of the flux tower at the agricultural site was influenced by several crop 163 types, the vegetation height and root depth were based on average simulations for winter- and 164 spring cereals. The observational data for leaf area index (LAI), another important crop parameter, 165 was inconsistent, and the seasonal variation of this parameter was therefore derived by combining 166 the observed seasonal trends and the simulation results by the Daisy model. The initial values for 167 soil parameters for each site were derived from the HYPRES pedotransfer function (Wösten et al. 168 1999). Specifically, the Van Genuchten parameters $\alpha$ and n (van Genuchten, 1980) as well as 
saturated hydraulic conductivity, residual- and saturated water content were estimated from soil texture, organic matter and bulk density. The soil texture data were retrieved from grid values from

171 a distributed soil map of $250 \mathrm{~m}$ resolution in the A horizon $(0-30 \mathrm{~cm})$ and $500 \mathrm{~m}$ resolution in $\mathrm{B}$ and C horizons (30-80 cm and below $80 \mathrm{~cm}$ ) (Styczen et al. 2004b, Greve et al. 2007, Iversen et al. 2011). For the sensitivity and optimization analyses the soil parameter bounds were defined by calculating the $90 \%$ confidence intervals of variation ranges from Meyer et al. (1997) for soils of similar texture as for the three field sites. These soil types include sand, loamy sand and sandy loam for the agriculture and forest site roughly corresponding to JB1 soil (coarse sand) in the Danish soil classification system (Greve et al. 2007, www.djfgeodata.dk). Due to the lack of agreement on soil type at the meadow site between site specific soil retention data and available soil maps the $90 \%$ confidence intervals for the meadow site is based on a wider range of soil types from loamy sand to clay loam (Meyer et al. 1997). The discrepancy of the data is most likely due to highly heterogeneous soils caused by shifting alluvial deposits from the nearby Skjern River. In the parameterization the seasonal patterns of vegetation characteristics as induced by both climate and management practice were kept constant whereas the respective amplitudes were calibrated by a single factor for each parameter. The annual sequence of these ratios was found by balancing model simulations by Daisy, relevant literature values (Table 1) and occasional on-site measurements of LAI and vegetation height. Similarly, the relation between the parameter values in the three vertical soil type horizons were kept constant implying that the individual parameters for the A, B and C horizon were shifted by the same factor for each grid cell. By introducing factors between parameters in space and time the number of parameters to be optimized is reduced.

The MIKE SHE model for catchment scale is based on the Danish national water resources model (DK-model) (Stisen et al. 2012, Højberg et al. 2013). As opposed to the DK-model the present model includes the SWET land-surface model and the parameterization of this model is 
193 partly based on the work by Stisen et al. (2011a). The DK model has a $500 \mathrm{~m}$ resolution and 194 includes a detailed river network. A maximum time step of 1 hour is used for overland, unsaturated 195 and saturated flow. The MIKE 11 open channel river model component utilizes 3616 cross sections 196 in 100 river branches and uses a 30 min time step. For precipitation exceeding $2 \mathrm{~mm}$ per time step 197 an automatic reduction in time step takes place. The input for the catchment scale SWET model is 198 hourly values of the same climatic variables as for the 1D models. These values are obtained by thin 199 plate spline interpolation of climate station data (Stisen et al. 2011a) to a resulting grid in $2 \mathrm{~km}$ 200 resolution for all variables except precipitation used in $500 \mathrm{~m}$ resolution. Precipitation input is 201 based on interpolation of daily rain gauge data using kriging and dynamically corrected for 202 undercatch. Simulated irrigation is subsequently added to precipitation. Hereafter, simulated 203 irrigation is added to the precipitation input file. The simulated irrigation is calculated from the root zone deficit and a demand function based on well locations, filter depths, annual abstractions and demand area information (Stisen et al. 2011b). The agricultural crop distribution was developed from statistical data, where the various crops were grouped in four classes with different growth 207 characteristics: spring sown cereals, winter sown cereals, grass/clover and maize. The crop classes 208 were distributed without georeferencing due to lack of data. Forest vegetation parameters were 209 based on relevant literature and observations. A total of 36 parameters were analysed in the 210 sensitivity analysis. As the calibration is targeted towards the energy fluxes no sensitivity and 211 calibration analyses are performed on the saturated zone parameterization which is already well 212 calibrated as a part of the DK-model (Stisen et al. 2012, Højberg et al. 2013).

213 To generate proper initial conditions for soil moisture in the 1D simulations a spin-up period 214 of 5-10 months prior to the calibration period was used. The spin-up periods were decided by data 215 availability as measurements started in April 2009 for the agriculture and meadow sites and 216 December 2008 for the forest site. The distributed model involves a considerable increase in 
computation time compared to the 1D setups and a spin-up period of 3 months was therefore used.

218 Groundwater quasi steady-state was reached by looping simulations in 3-year runs each time using 219 the resulting groundwater heads as initial conditions for the subsequent simulation. Three loops 220 were required to reach quasi steady-state.

\subsection{Calibration approach}

We propose a calibration and validation approach involving three steps as illustrated in

224 Figure 2: (1) calibration of 1D models representing the flux measurement sites, (2) use of parameter values from step 1 as initial values in the calibration of the distributed catchment model, and (3) validation of the distributed parameterization on independent data. Additionally we test the calibration results by comparing to model results based on $1 \mathrm{D}$ calibration only and with no calibration respectively.

Both the 1D and the distributed simulations were calibrated using inverse modelling 230 adopting initial and range of parameter values from literature, observations, databases and 231 simulation results from the model code Daisy (Hansen et al. 1990, 1991) as described above and as 232 listed in Table 1 and 2. The initial input parameter values as well as their ranges were specified 233 according to relevance: If available, either observations or Daisy model simulations based on site 234 specific conditions were used. When using literature values conditions similar to the sites in terms 235 of vegetation species, climate and soil type were used. The calibration period covers a one year 236 period from October 1, 2009 to September 30, 2010 while the validation period is from May 1, 2372011 to April 30, 2012.

The sensitivity and auto-calibration analyses were performed using the AUTOCAL software 239 included in the MIKE SHE package (Madsen 2003). At the point scale three components were 240 included in the objective function: latent heat flux LE, sensible heat flux $\mathrm{H}$, and averaged soil water 
241 content based on measurements at three depths $(2.5,22.5$ and $52.5 \mathrm{~cm}$ below the surface). The 242 objective function was built from the root mean square errors (RMSE) between observations and 243 simulations. The RMSEs for the three individual components were normalized, weighted equally 244 and summed to arrive at an aggregated objective function. The normalization was carried out using 245 the common distance scale which has proven to be robust in accounting for differences in 246 magnitude of each component of the objective function (Madsen 2003, Butts et al. 2004, Mertens et 247 al. 2004).

248 At catchment scale the optimization was performed against two overall components of equal 249 weight: (1) Discharge observations at three discharge stations aggregated with equal weight (Figure 250 1) and (2) latent and sensible energy fluxes at the three sites weighted according to the relative areal 251 share of each land surface type (agriculture 62\%, forest $13 \%$ and grass/meadow $25 \%$ ). The sensitivity analysis (Step 1.2 and 2.2 in Figure 2) for both point and catchment scales 253 were based on the AUTOCAL local sensitivity analysis procedure accounting for parameter 254 sensitivities at the location in parameter space defined by the initial parameter values. Since the 255 sensitivity analysis was local and therefore unable to account for numerous combinations in the 256 parameter space, the sensitivity analyses were repeated using randomly sampled parameter sets 257 within the parameter bounds. The sensitivity analysis was based on a backward difference 258 approximation method around the parameter value using a $2 \%$ perturbation fraction. Also, 259 covariance matrices were calculated to test for parameter correlation.

260 For both scales the ten most sensitive parameters were identified and subsequently used in 261 the auto-calibration process similar to Blasone et al. (2007). Only parameters with relative 262 sensitivity coefficients above $1 \%$, in relation to the most sensitive parameter, were included in the 263 optimization (Hill 1998). For the low sensitivity parameters that were not included in the auto- 
calibration of the catchment model their values were derived from the point scale calibrations. The remaining distributed parameters were based on relevant literature (Table 2).

The point scale parameter optimization was based on the global Shuffled Complex Evolution method (Duan et al. 1993) which has proven to be robust for comprehensive parameter estimation problems (Butts et al. 2004, Mertens et al. 2005, Blasone et al. 2007). A maximum time step of 6 minutes was used for the 1D models, which for the calibration period corresponded to a computation time of around 2-3 minutes per model run. The model convergence criteria were defined as max. $1 \%$ change in objective function after three iterations loops and this criterion was usually met after 200-250 runs. For obtaining a more efficient optimization of the catchment scale model, parallel model runs were carried out using the global Population Simplex Evolution optimization method (DHI 2010). The convergence criterion was typically reached after 250-400 runs.

To assess the accuracy of the parameterization and modelling approach as such, an independent validation analysis was performed subsequent to the auto-calibration simulations. The validation was performed for a one-year period and assessed on discharge, LE and $\mathrm{H}$ as for the calibration analysis (Step 3.1, Figure 2).

\subsection{Handling of Energy Balance Flux problems}

Energy balance closure requires that the net radiation (difference between incoming and outgoing long- and short-wave radiation) equals the sum of latent heat (LE), sensible heat (H), and

284 soil heat $(\mathrm{G})$ fluxes. All terms are highly sensitive to the surface characteristics and furthermore 285 they are subject to different diurnal and seasonal variations. The albedo of bare soil is dependent on texture and moisture content while the albedo for vegetation generally decreases with vegetation height and stand complexity. Changes in albedo will affect the amount of available energy, and soil 
moisture influences how this energy is distributed between LE and $\mathrm{H}$ heat fluxes. Independent measurements of the components of the energy balance equation rarely provide closure, which has been documented in numerous studies (Wilson et al. 2002, Franssen et al. 2010, Leuning et al. 291 2012).

The impact of the energy balance closure problem on the calibration results was addressed 293 by creating four hypotheses each based on different assumptions regarding measurement errors 294 (Step 1.4 and 2.4, Figure 2). All four hypotheses were used for the 1D runs whereas only the first two were used in the distributed runs to reduce computation time.

- $\quad$ HYP1: The measured energy fluxes (LE, H and G) are scaled with a single factor (increase) such that the Bowen-ratio is maintained and the sum of the energy fluxes equals measured

- $\quad$ HYP2: The measured energy fluxes are maintained whereas the net radiation is scaled with a factor (reduction) to match the sum of measured energy fluxes over the one-year calibration period;

- HYP3: The measured energy fluxes are unaltered whereas the sum of these is used as net radiation on a daily basis;

- $\quad$ HYP4: The measured energy fluxes (LE, H and G) are scaled with a single factor (increase) such that the Bowen-ratio is maintained and the sum of the energy fluxes equals measured net radiation on a daily basis;

which is the case for the last two scenarios. Of the investigated scenarios more energy is available in HYP1 and HYP4 based on the measured net radiation (yearly mean values of $55 \mathrm{w} / \mathrm{m}^{2}, 68 \mathrm{w} / \mathrm{m}^{2}$ 
311 and $55 \mathrm{w} / \mathrm{m}^{2}$ for agriculture, forest and meadow respectively) whereas HYP2 and HYP3 are based 312 on reduced values (yearly mean values of $39 \mathrm{w} / \mathrm{m}^{2}, 48 \mathrm{w} / \mathrm{m}^{2}$ and $42 \mathrm{w} / \mathrm{m}^{2}$ for the same sites).

313 Only the HYP1 and HYP2 hypotheses were used for the distributed simulations since they 314 both utilize measured net radiation, scaled and unscaled, and hereby the daily temporal pattern is 315 likely to be more representative than if based on the sum of the three fluxes. In contrast to the point 316 scale where net radiation measurements were available, global radiation was used in the catchment 317 scale analysis. To fulfil the same assumptions on energy balance closure as used at point scale the 318 albedo was adjusted to obtain energy balance closure over the entire one year calibration period. 319 This was done based on the flux measurements for the three general land use types agriculture, 320 forest and meadow. As a result HYP1 is based on measured albedos whereas HYP2 is based on 321 estimated albedos that are higher than measured. All three distributed simulation cases shown in 322 Figure 2 were performed for both HYP1 and HYP2 as well as for the calibration and validation 323 periods for a total of 12 simulations.

\section{Results}

\subsection{Energy balance closure}

The measurements used in this study show lack of energy balance closure. The sum of LE, $\mathrm{H}$ and $\mathrm{G}$ over the one-year calibration period accounted for $71 \%, 71 \%$ and $76 \%$ of the measured net radiation at the agricultural, forest and meadow/grass sites respectively (Figure 3). The 330 corresponding measured Bowen-ratios in the same period were $0.20,0.17$ and 0.18 for the three 331 land surface types. Radiation and particularly data for energy fluxes are generally sparse in 332 Denmark. Therefore, in Figure 3, measured net and global radiation as well as the sum of energy 333 fluxes are compared to results from (1) the corresponding grid cell in HIRHAM regional climate 334 model simulations (Larsen et al. 2013) using ERA-Interim reanalysis data as boundary conditions 
and (2) observation data from the Foulum research station (grass surface) located app. $50 \mathrm{~km}$ north of the agriculture and forest sites. HIRHAM simulation data are also used to compare LE and $\mathrm{H}$ fluxes since no other flux data were available. The simulations of net radiation by HIRHAM and the observed data from Foulum are much closer to measured LE, H and G flux sum at all sites for both years although perhaps less distinct at the forest site (Figure 3). For global radiation there is a close match between all data series, especially between the three study sites and Foulum. For LE fluxes good agreement is seen between HIRHAM simulations and observations for the forest and meadow sites and less favourable for the agricultural site. For the $\mathrm{H}$ fluxes larger discrepancies are seen particularly for the forest site.

\subsection{Simulation results}

The results of the sensitivity analyses for both point and catchment scales are shown in

347 Figure 4. Similar parameter sensitivity results are obtained for the agricultural and forest sites with nine and ten parameters, respectively, having a relative sensitivity coefficient above $10 \%$. The parameter sensitivities for hypotheses HYP2 and HYP3 (with unaltered energy fluxes) show similar patterns with the minimal stomata resistance (Rst_min) as the most sensitive parameter. In contrast,

351 for hypotheses HYP1 and HYP4 (with corrected energy fluxes) the root shape factor is the most sensitive parameter. For the meadow site only the three parameters Rst_min, leaf area index (LAI) and vegetation height have relative sensitivity coefficients above $10 \%$ and the influence of the energy balance hypothesis is limited given the large drop in sensitivity between Rst_min and the second most sensitive parameter LAI.

At catchment scale saturated hydraulic conductivity (K_sat) for the unsaturated zone is the most sensitive parameter for both energy balance hypotheses, whereas the sensitivities of the remaining parameters are smaller and also subject to larger variation between the two hypotheses 
359 (Figure 4). The forest energy fluxes were found to be poorly reproduced by the calibrated forest leaf 360 width values which were therefore manually calibrated prior to auto-calibration.

The simulated discharge based on the parameter values obtained by the full auto-calibration approach for the two distributed energy balance hypotheses are shown in Figure 5 for both the calibration and validation periods. For both simulations and periods there is a tendency of underestimation of baseflow and mostly pronounced for HYP2. For peak flow the HYP2 hypothesis exhibits more dynamic behaviour with more rapid responses. In summary, the HYP1 simulation shows better discharge performance statistics for the calibration period whereas the opposite pattern is seen for the validation period (Figure 6). Also, the validation confirms a reasonable discharge calibration although the HYP1 results are moderately poorer for two out of three discharge stations. period in the calibration period. The results from the two energy hypothesis runs are compared to their relevant fluxes: HYP1 to scaled and HYP2 to unscaled fluxes, corresponding to the assumptions of the energy balance closure. For both the calibration and validation periods, there is a tendency for better energy flux statistics for HYP2 compared to HYP1 (Figure 6). Overall the agriculture and grass surfaces are better reproduced compared to forest. Especially observations of $375 \mathrm{H}$ in the forest are rather poorly simulated during high global radiation (Figure 7); however, part of this discrepancy is likely caused by errors in the observation data (Sonnenborg et al. 2013).

377 Simulations for night time conditions compare favourably to observations of both energy fluxes and 378 for both scenarios. As shown in Figure 6 the simulations for the validation period shows 379 comparable or better performance statistics for both fluxes as compared to the calibration period. In the auto-calibration, simulations are compared to the same observed discharge data for 381 both HYP1 and HYP2 while the energy fluxes and albedos were adjusted to obtain energy balance 382 closure. This is reflected by differences in water balance components for the two hypotheses HYP1 
and HYP2 both on catchment and local scales (Table 3). With a lower albedo in the HYP1 scenario

384 higher ET and therefore lower recharge and discharge are simulated at catchment scale. For the 385 agriculture grid cell the slightly higher ET for the HYP2 hypothesis can be ascribed to the lower 386 K_sat value. The significant difference in drainage is likely a function of higher groundwater 387 elevations in the HYP2 hypothesis. For forest and meadow the difference in albedo is reflected in 388 higher ET for HYP1.

The comparison of the performances of the full calibration and the scenarios with calibration 390 of the 1D models only and no calibration respectively is shown in figure 6 . For discharge the 391 simulations with no calibration using default values is comparable to the results of the full 392 calibration whereas the 1D calibration is generally poorer. The most significant improvement in the 393 calibration approach is however seen for the LE and $\mathrm{H}$ energy fluxes where the mean root mean square error (RMSE) and mean absolute error (MAE) statistics for the three sites is substantially improved. The distributed simulations based on the values from the $1 \mathrm{D}$ calibration transferred to catchment scale are generally of lower quality compared to the case where no calibration is carried out. This, as opposed to using initial values using no calibration at all (default values), is because neither input source includes parameters related to the distributed scale (e.g. related to discharge and overland flow). Also, the extreme 1D mean RMSE statistics for $\mathrm{H}$ is due to the forest site which was manually calibrated prior to the autocalibration (see above) and it does therefore not affect the 401 full 1D+2D calibration.

\section{Discussion}

We have presented an approach for a stepwise calibration of a distributed combined land 405 surface/hydrology model using observations of energy fluxes and discharge as calibration target. In 406 general the method proved effective. The validation period confirmed the performance statistics 
407 from the calibration period and the simulations using a reduced calibration approach or no 408 calibration were generally less accurate.

\subsection{Energy and water balance}

As expected a key finding was that the choice of energy balance hypothesis has a major 412 impact on the resulting parameterization as well as on the energy and water balance results. The 413 lack of energy balance closure for flux measurements is therefore a great challenge when using such 414 measurements for calibrating distributed hydrological models. Energy balance closure is required 415 when flux measurements are used for inverse modelling and we investigated two hypotheses where 416 the error was attributed to either the measured energy fluxes (HYP1) or the measured net radiation 417 (HYP2).

418 Either of these two approaches may be applicable. Even though the eddy covariance method 419 is generally regarded as the best practical method for measuring energy fluxes, measurement 420 difficulties are well documented (Foken et al. 2006, Sun et al. 2008, Franssen et al. 2010, Ringgard, 421 2012, Stoy et al. 2013). A consistent deficit in measured LE fluxes have been suggested as an 422 explanation in the lack of energy balance closure (Sun et al. 2008) while on the other hand Foken et 423 al. (2006) suggested that low frequency turbulence structures cause errors in the flux measurements. 424 Also, measurement errors in $\mathrm{H}$ fluxes have been suggested, see (Mauder et al. 2008) and 425 Sonnenborg et al. (2013). The energy flux statistics (Figure 6) were better for the HYP2 hypothesis 426 possibly indicating that larger measurement errors are attributed to the energy fluxes compared to 427 radiation components. An additional contributing factor is the difference in the footprint of the flux 428 measurements reflecting conditions upstream of the wind direction and the support scale of the 429 radiation sensor. 
Contrary to indications of flux measurement biases, estimates of ET based on eddy

431 covariance and soil moisture balances of the root zone compared well and surprisingly the highest

432 ET was seen for the eddy covariance method over a seven week period in May-June 2009 (Schelde 433 et al. 2011). Similarly, net radiation measurements from Foulum research station match the sum of 434 LE, $\mathrm{H}$ and $\mathrm{G}$ fluxes better than for the agriculture, forest and meadow sites used in this study 435 (Figure 3). Advection has also been suggested as a missing component in the energy balance 436 suggesting that the measured energy fluxes may indeed be more reliable than anticipated (Leuning et al. 2012). Likewise, large scale eddies due to land surface heterogeneity have recently been suggested to make up a part of the energy imbalance (Stoy et al. 2013).

Snow processes are currently not considered the SWET land-surface model and this impacts 440 the calibration results especially with regard to discharge. Even though the calibration period is 441 relatively cold, little precipitation occurs on days with temperatures below $0{ }^{0} \mathrm{C}$. Nevertheless, the snow melt related discharge peaks in Feb-Mar 2010 are clearly not reproduced (Figure 5).

\subsection{Sensitivity, calibration and validation}

The distinct differences between parameter sensitivities at the agriculture and forest sites compared to the meadow site are related to the water available for ET (Figure 8). At the agricultural and forest sites, complete soil saturation is rarely or never reached and there is a clear tendency for higher ET with lower soil moisture as this occurs during the summer months with a higher level of

449 available solar energy. Soil parameters affecting available soil water are therefore crucial for 450 determining the partitioning of energy fluxes at these sites. For the meadow site, located next to the 451 river bank, saturated conditions are often reached (41\% of the year for HYP2) and soil moisture levels are generally high. As a result the relation between root zone water and ET is less distinct. 
The high water availability at the meadow site therefore makes vegetation parameters substantially more important compared to soil parameters.

The choice of energy balance closure hypothesis, and therefore the energy available, is highly influential on which parameters are most sensitive especially for the agriculture and forest sites but also to some extent for the meadow site. This is reflected in the sensitivities for the HYP1 and HYP4 hypotheses on one side and the HYP2 and HYP3 hypotheses on the other. This is consistent with the HYP1/HYP4 hypotheses being based on measured net radiation (averaged to 54, 67 and $56 \mathrm{~W} / \mathrm{m}^{2}$ in the calibration period for agriculture, forest and meadow) while the HYP2/HYP3 hypotheses are based on downscaled net radiation $\left(40,47\right.$ and $40 \mathrm{~W} / \mathrm{m}^{2}$ for the same 462 sites).

The results of the sensitivity analysis and auto-calibration procedure naturally reflect the 464 interplay between a vast number of parameters, assumptions regarding the energy balance terms, assumed relations between parameters for the individual soil layers, and the specific conditions that apply for the period subject to the analysis. These assumptions are required for reasons such as energy balance closure, calibration simplicity, data availability and focus of the study in question.

468 For example, the parameter Rst_min is assumed constant in the present study whereas Ingwersen et 469 al. (2011) obtained better simulations of LE and H based on the Noah LSM model using monthly 470 values of Rst_min. Hou et al. (2012) related simulations of LE and H to parameter uncertainty in a 471 study using the Community Land Model (CLM4) and documented substantial variations in the 472 simulations of both fluxes (over $100 \mathrm{~W} / \mathrm{m}^{2}$ ) in the summer months depending on the 473 parameterization. The rather poor agreement between simulations and observations of $\mathrm{H}$ fluxes was 474 likely due to observation errors. Separate auto-calibration runs were performed assessing forest heat 475 fluxes based on forest parameterization alone with limited improvement and this is in line with the results by Sonnenborg et al. (2013). 
5.3 Land use

Standard seasonal crop characteristics were used in this study and the actual crop rotation and management conditions at a given site were therefor not considered. This could lead to 481 discrepancies between the vegetation parameterization at the agricultural site particular around the 482 time of harvest and at the grass site due to irregular and undocumented cattle grazing. Possibly 483 more significant is the effect of the spatial distribution of crops derived from available county average data, which may not reflect the actual distribution. This is the case both in terms of the overall distribution, type and location of crops within the catchment. But it also affects the evaluation of energy flux data from the agricultural site as the actual footprint may differ from the simulated crop as also reported by Göckede et al. (2008).

The distributed MIKE SHE parameterization was performed by transferring the calibrated parameters from the point scale setups, representing agriculture, meadow and forest, to the relevant land surfaces within the catchment for subsequent sensitivity and auto-calibration analyses. For agriculture, this procedure includes the tradeoff between using the calibrated parameter values reflecting site specific conditions at the measurement site and using crop and soil specific parameters from the Daisy model. However, the former was used since parameters were calibrated under conditions of energy balance closure but also because of the statistical spatial distribution of the Daisy modelled crop characteristics.

\section{6 - Conclusions}

In the present study we present a novel approach to calibrating a combined and distributed 499 hydrology/land-surface model. The approach first involves calibration of the land-surface model 500 component against measurements of energy fluxes from flux towers. Secondly, the distributed 
501 hydrological model component, including unsaturated and saturated zone components, is calibrated using the point scale parameterization as initial conditions and using stream flow and energy flux measurements as the calibration targets. The method employs a meticulous literature inspection for realistic initial and range of parameter values. Previous calibration efforts of SVAT and LSM models with a hydrological focus have often used satellite data having certain measurement 506 deficiencies, relied on previously point scale based parameterizations or used traditional 507 hydrological variables such as discharge and hydraulic head. Modelling the highly interrelated and 508 dynamical processes and variables in the entire water and energy budget from groundwater to lower 509 atmosphere is challenging. Our results show that the proposed approach significantly improves the 510 simulated energy balance components as compared to using default values or a simpler 1D 511 calibration. The simulations were able to reproduce features across water and energy budgets taking 512 into considerations measurement errors and lack of energy balance closure.

513 The calibration of the one dimensional models provided good insight to data quality and 514 parameter sensitivity and served as a useful initial parameterization of the catchment scale 515 simulations. Further, the sensitivities of parameters in the point scale analysis were highly affected 516 by the surface type and more specifically the water availability as well as the choice of energy 517 balance hypothesis. Similarly, the catchment model simulations showed that parameter sensitivities 518 are largely determined by the choice of energy balance hypothesis, yet saturated hydraulic 519 conductivity was the most sensitive parameter for both energy balance hypotheses. Despite likely 520 errors in measured forest sensible heat fluxes, our results suggest that the measured energy fluxes 521 are reliable and that the energy imbalance is likely caused by advection and large scale eddies rather 522 than erroneous net radiation measurements. 
525 The present study was funded by a grant from the Danish Strategic Research Council for the project 526 HYdrological Modelling for Assessing Climate Change Impacts at differeNT Scales (HYACINTS527 www.hyacints.dk) under contract no: DSF-EnMi 2104-07-0008. The study is made possible 528 through a collaboration with the HOBE project (www.hobecenter.dk) funded by the Villum Kann 529 Rasmussen Foundation. The data used in the study can be accessed through the first author.

- Allerup, P., Madsen, H., Vejen, F., 1998. Standardværdier (1961-90) af Nedbørkorrektioner, Danish 536 Meteorological Institute Technical Report 98-10, Denmark.

- Barr, A.G., van der Kamp, G., Black, T.A., McCaughey, J.H., Nesic, Z., 2012. Energy balance closure at the BERMS flux towers in relation to the water balance of the White Gull Creek watershed 1999-2009. Agric. Forest Meteorol. 153, 3-13. doi:10.1016/j.agrformet.2011.05.017.

541 nutrient input to a Norway spruce plantation at Klosterhede, Denmark. Plant Soil 168, 613-622.

- Beven, K.J., Franks, S.W., 2001. Functional similarity in landscape scale SVAT modelling. Hydrol. 543 Earth Syst. Sc. 3, 85-93. doi:10.5194/hess-3-85-1999

- Beven, K., 2006. Searching for the Holy Grail of scientific hydrology: Q t=(S, R,? t) A as closure. 545 Hydrol. Earth Syst. Sc. Discussions 10, 609-618. doi:10.5194/hess-10-609-2006.

546 - Blasone, R. S., Madsen, H., Rosbjerg, D., 2007. Parameter estimation in distributed hydrological 547 modelling: comparison of global and local optimisation techniques, Nord. Hydrol. 38(4-5), 451-476, doi:10.2166/nh.2007.024.

- Boulet, G., Kalma, J.D., Braud, I., Vauclin, M., 1999. An assessment of effective land surface parameterisation in regional-scale water balance studies. J. Hydrol. 217, 225-238. 
- Breda, N.J.J., 2003. Ground-based measurements of leaf area index: a review of methods, instruments and current controversies. J. Exp. Bot. 54, 2403-2417. doi:10.1093/jxb/erg263

- Butts, M. B., Payne, J. T., Kristensen, M., Madsen, H., 2004. An evaluation of the impact of model structure on hydrological modelling uncertainty for streamflow simulation, J. Hydrol. 298, 242-266, doi:10.1016/j.jhydrol.2004.03.042.

- Butts, M., Drews, M., Larsen, M.A.D., Lerer, S., Rasmussen, S.H., Grooss, J., Overgaard, J., Refsgaard, J.C., Christensen, O.B., Christensen, J.H., 2014. Embedding complex hydrology in the regional climate system - Dynamic coupling across different modelling domains. Adv. Water Resour. 74, 166-184. doi:10.1016/j.advwatres.2014.09.004

- Boegh, E., Poulsen, R.N., Butts, M., Abrahamsen, P., Dellwik, E., Hansen, S., Hasager, C.B., Ibrom, A., 561 Loerup, J.-K., Pilegaard, K., Soegaard, H., 2009. Remote sensing based evapotranspiration and runoff 562 modeling of agricultural, forest and urban flux sites in Denmark: From field to macro-scale. J. Hydrol. 563 377, 300-316. doi:10.1016/j.jhydrol.2009.08.029

564 - Chen, F., Dudhia, J., 2001a. Coupling an Advanced Land Surface-Hydrology Model with the Penn 565 State-NCAR MM5 Modeling System. Part I: Model Implementation and Sensitivity. Mon. Wea. Rev. 129, 569-585. doi:10.1175/1520-0493(2001)129<0569:CAALSH>2.0.CO;2

- Choi, M., Kustas, W.P., Anderson, M.C., Allen, R.G., Li, F., Kjaersgaard, J.H., 2009. An intercomparison of three remote sensing-based surface energy balance algorithms over a corn and soybean production region (Iowa, U.S.) during SMACEX. Agric. For. Meteorol. 149, 2082-2097. doi:10.1016/j.agrformet.2009.07.002

- Crow, P., 2005. The Influence of Soils and Species on Tree Root Depth, Environmental and Human Sciences Division, Forest Research. ISBN 0-85538-679-7, United Kingdom.

- Dai, Z., Li, C., Trettin, C., Sun, G., Amatya, D., Li, H., 2010. Bi-criteria evaluation of the MIKE SHE model for a forested watershed on the South Carolina coastal plain. Hydrol. Earth Syst. Sc. 14, 10331046. doi:10.5194/hess-14-1033-2010. 
- Demarty, J., Ottlé, C., Braud, I., Olioso, A., Frangi, J., Bastidas, L., Gupta, H., 2004. Using a 577 multiobjective approach to retrieve information on surface properties used in a SVAT model. J. Hydrol. $578 \quad$ 287, 214-236. doi:10.1016/j.jhydrol.2003.10.003

- DHI, 2010. AUTOCAL - Auto Calibration Tool, User Guide. MIKE by DHI Software, Hørsholm, 580 Denmark.

581 - Duan, Q., Gupta, V. K., Sorooshian, S., 1993. A shuffled complex evolution approach for effective and 582 efficient global minimization, J Optimiz. Theory. Ap., 76, 501-521.

583 - Ewers, B.E., Oren, R., Johnsen, K.H., Landsberg, J.J., 2001. Estimating maximum mean canopy stomatal 584 conductance for use in models. Can. J. Forest Res. 31, 198-207. doi:10.1139/cjfr-31-2-198

585 - Foken T, Wimmer, F., Mauder, M., Thomas, C., Liebethal, C., 2006. Some aspects of the energy balance 586 closure problem, Atmos. Chem. Phys., 6, 3381-3402, doi:10.5194/acp-6-4395-2006.

- Frank, A.B., Bittman, S., Johnson, D.A., 1996. Water relations of cool-season grasses. Cool-season 588 forage grasses, L.E. Moser et al. (ed.), Agron. Monogr., 34, 127-164, ASA, CSSA, SSSA, Madison, $589 \quad$ Wisconsin, USA.

590 - Franks, S.W., Beven, K.J., Quinn, P.F., Wright, I.R., 1997. On the sensitivity of soil-vegetation591 atmosphere transfer (SVAT) schemes: equifinality and the problem of robust calibration. Agric. For. $592 \quad$ Meteorol. 86, 63-75. doi:10.1016/S0168-1923(96)02421-5

593 - Franks, S.W., Beven, K.J., Gash, J.H.C., 1999. Multi-objective conditioning of a simple SVAT model. $594 \quad$ Hydrol. Earth Syst. Sc. Discussions 3, 477-488.

595 - Franssen, H.J.H., Stöckli, R., Lehner, I., Rotenberg, E., Seneviratne, S.I., 2010. Energy balance closure 596 of eddy-covariance data: A multisite analysis for European FLUXNET stations. Agric. For. Meteorol. $597 \quad$ 150, 1553-1567. doi:10.1016/j.agrformet.2010.08.005

598 - Graham, D. N., Butts, M.B., 2005. Flexible, integrated watershed modelling with MIKE SHE, In 599 Watershed Models, Eds. V.P. Singh \& D.K. Frevert, 245-272, CRC Press. ISBN: 0849336090. 
- Greve, M.H., Greve, M.B., Bøcher, P.K., Balstrøm, T., Breuning-Madsen, H., Krogh, L., 2007.

601 Generating a Danish raster-based topsoil property map combining choropleth maps and point 602 information. Geografisk Tidsskrift-Danish Journal of Geography 107, 1-12.

604 latitude forest under winter conditions. Bound.-Layer Meteor. 99, 465-488.

- Göckede, M., Foken, T., Aubinet, M., Aurela, M., Banza, J., Bernhofer, C., Bonnefond, J.M., Brunet, Y., Carrara, A., Clement, R., Dellwik, E., Elbers, J., Eugster, W., Fuhrer, J., Granier, A., Grünwald, T., Heinesch, B., Janssens, I.A., Knohl, A., Koeble, R., Laurila, T., Longdoz, B., Manca, G., Marek, M., Markkanen, T., Mateus, J., Matteucci, G., Mauder, M., Migliavacca, M., Minerbi, S., Moncrieff, J., Montagnani, L., Moors, E., Ourcival, J.-M., Papale, D., Pereira, J., Pilegaard, K., Pita, G., Rambal, S., Rebmann, C., Rodrigues, A., Rotenberg, E., Sanz, M.J., Sedlak, P., Seufert, G., Siebicke, L., Soussana, J.F., Valentini, R., Vesala, T., Verbeeck, H., Yakir, D., 2008. Quality control of CarboEurope flux data Part 1: Coupling footprint analyses with flux data quality assessment to evaluate sites in forest ecosystems. Biogeosciences 5, 433-450. doi:10.5194/bg-5-433-2008

- Grimmond, C.S.B., Blackett, M., Best, M.J., Barlow, J., Baik, J.-J., Belcher, S.E., Bohnenstengel, S.I., Calmet, I., Chen, F., Dandou, A., Fortuniak, K., Gouvea, M.L., Hamdi, R., Hendry, M., Kawai, T., Kawamoto, Y., Kondo, H., Krayenhoff, E.S., Lee, S.-H., Loridan, T., Martilli, A., Masson, V., Miao, S., Oleson, K., Pigeon, G., Porson, A., Ryu, Y.-H., Salamanca, F., Shashua-Bar, L., Steeneveld, G.-J., Tombrou, M., Voogt, J., Young, D., Zhang, N., 2010. The International Urban Energy Balance Models Comparison Project: First Results from Phase 1. J. Appl. Meteorol. 49, 1268-1292. doi:10.1175/2010JAMC2354.1

- Gupta, H.V., Sorooshian, S., Yapo, P.O., 1998. Toward improved calibration of hydrologic models: Multiple and noncommensurable measures of information. Water Resour. Res. 34, 751-763. doi:10.1029/97WR03495

- Gupta, H.V., Bastidas, L.A., Sorooshian, S., Shuttleworth, W.J., Yang, Z.L., 1999. Parameter estimation of a land surface scheme using multicriteria methods. J. Geophys. Res. (1984-2012) 104, 19491-19503. 
- Hansen, S., Jensen, H. E., Nielsen, N. E., Svendsen H., 1990. Daisy: Soil-plant-atmosphere system model. NPO National Agency of Environmental Protection Research Report No. A10. Copenhagen, 628 Denmark.

629 - Hansen, S., Jensen, H. E., Nielsen, N. E., Svendsen H., 1991. Simulation of nitrogen dynamics and 630 biomass production in winter wheat using the Danish simulation model DAISY. Fert. Res., 27, 245-259.

631 - Hassan, Q.K., Bourque, C.P.-A., 2010. Spatial Enhancement of MODIS-based Images of Leaf Area 632 Index: Application to the Boreal Forest Region of Northern Alberta, Canada. Remote Sens. 2, 278-289. 633 doi:10.3390/rs2010278

634 - Hill, M.C., 1998. Methods and Guidelines for Effective Model Calibration. U.S. Geological Survey 635 Water-Resources Investigations Report 98-4005, USA.

636 - Hou, Z., Huang, M., Leung, L. R., Lin, G., Ricciuto, D. M., 2012. Sensitivity of surface flux simulations 637 to hydrologic parameters based on an uncertainty quantification framework applied to the Community 638 Land Model, J. Geophys. Res., 117, D15108, doi:10.1029/2012JD017521.

639 - Hussein, A.S., 1999. Grass ET estimates using Penman-type equations in Central Sudan. J. Irrig. Drain. $640 \quad$ Eng. $125,324-329$.

641 - Højberg, A. L., Troldborg, L., Stisen, S., Christensen, B. B. S., Henriksen, H. J., 2013. Stakeholder 642 driven update and improvement of a national water resources model, Environ. Modell. Softw., 40, 202643 213. doi:10.1016/j.envsoft.2012.09.010

644 - Ingwersen, J., Steffens, K., Högy, P., Warrach-Sagi, K., Zhunusbayeva, D., Poltoradnev, M., Gäbler, R., 645 Wizemann, H.-D., Fangmeier, A., Wulfmeyer, V., Streck, T., 2011. Comparison of Noah simulations with 646 eddy covariance and soil water measurements at a winter wheat stand. Agric. For. Meteorol. 151, 345647 355. doi:10.1016/j.agrformet.2010.11.010

648 - Iversen, B. V., Børgesen, C. D., Lægdsmand, M., Greve, M. H., Heckrath, G., Kjærgaard, C., 2011. Risk 649 Predicting of Macropore Flow using Pedotransfer Functions, Textural Maps, and Modeling. Vadose Zone $650 \quad$ J., 10, 1185-1195, doi:10.2136/vzj2010.0140. 
- Jensen, K.H., Illangasekare, T. H., 2011. HOBE: A Hydrological Observatory. Vadoze Zone J. 10, 1-7, doi:10.2136/vzj2011.0006.

- Kelliher, F.M., Leuning, R., Raupach, M.R., Schulze, E.-D., 1995. Maximum conductances for evaporation from global vegetation types. Agr. Forest. Meteorol.73, 1-16. doi:10.1016/01681923(94)02178-M

- Lagergren, F., Eklundh, L., Grelle, A., Lundblad, M., Mölder, M., Lankreijer, H., Lindroth, A., 2005. Net primary production and light use efficiency in a mixed coniferous forest in Sweden. Plant, Cell \& Environ. 28, 412-423. doi:10.1111/j.1365-3040.2004.01280.x

- Lantinga, E.A., Nassiri, M., Kropff, M.J., 1999. Modelling and measuring vertical light absorption 661 - Larsen, M. A. D., Thejll, P., Christensen, J. H., Refsgaard, J. C., Jensen, K. H., 2013. On the role of 662 domain size and resolution in the simulations with the HIRHAM region climate model, Clim Dyn 40, 663 2903-2918, doi:10.1007/s00382-012-1513-y.

- Larsen, M.A.D., Refsgaard, J.C., Drews, M., Butts, M.B., Jensen, K.H., Christensen, J.H., Christensen, 665 O.B., 2014. Results from a full coupling of the HIRHAM regional climate model and the MIKE SHE 666 hydrological model for a Danish catchment. Hydrol. Earth. Syst. Sc. 18, 4733-4749. doi:10.5194/hess18-4733-2014

- $\quad$ Lawrence, D.M., Oleson, K.W., Flanner, M.G., Thornton, P.E., Swenson, S.C., Lawrence, P.J., Zeng, X., 703-724. doi:10.1016/j.ecolmodel.2008.11.023

- Lazzarotto, P., Calanca, P., Semenov, M., Fuhrer, J., 2010. Transient responses to increasing CO2 and climate change in an unfertilized grass-clover sward. Clim. Res. 41, 221-232. doi:10.3354/cr00847 
- Leuning, R., van Gorsel, E., Massman, W.J., Isaac, P.R., 2012. Reflections on the surface energy 678 imbalance problem. Agric. For. Meteorol. 156, 65-74. doi:10.1016/j.agrformet.2011.12.002

- Li, H., Huang, M., Wigmosta, M.S., Ke, Y., Coleman, A.M., Leung, L.R., Wang, A., Ricciuto, D.M., 680 2011. Evaluating runoff simulations from the Community Land Model 4.0 using observations from flux 681 towers and a mountainous watershed. J. Geophys. Res. 116, (D24120). doi:10.1029/2011JD016276

- Lindroth, A., Lagergren, F., Aurela, M., Bjarnadottir, B., Christensen, T., Dellwik, E., Grelle, A., Ibrom, 683 A., Johansson, T., Lankreijer, H., Launiainen, S., Laurila, T., MöLder, M., Nikinmaa, E., Pilegaard, K., 684 Sigurdsson, B.D., Vesala, T., 2008. Leaf area index is the principal scaling parameter for both gross 685 photosynthesis and ecosystem respiration of Northern deciduous and coniferous forests. Tellus B 60, 686 129-142. doi:10.1111/j.1600-0889.2007.00330.x

687 - Madsen, H., 2003. Parameter estimation in distributed hydrological catchment modelling using 688 automatic calibration with multiple objectives. Adv. Water Resour. 26, 205-216.

689 - Mauder, M., Desjardins, R. L., Pattey, E., Gao, Z., van Haarlem, R., 2008. Measurement of the Sensible 690 Eddy Heat Flux Based on Spatial Averaging of Continuous Ground-Based Observations. Bound.-Layer $691 \quad$ Meteorol. 128, 151-172. doi:10.1007/s10546-008-9279-9

- Maurer, E.P., Wood, A.W., Adam, J.C., Lettenmaier, D.P., Nijssen, B., 2002. A long-term hydrologically 693 based dataset of land surface fluxes and states for the conterminous United States. J. Climate 15, 32376943251.

695 - Mauser, W., Schädlich, S., 1998. Modelling the spatial distribution of evapotranspiration on different 696 scales using remote sensing data. J. Hydrol. 212, 250-267.

697 - Maxwell, R.M., Lundquist, J.K., Mirocha, J.D., Smith, S.G., Woodward, C.S., Tompson, A.F.B., 2011. 698 Development of a Coupled Groundwater-Atmosphere Model. Mon. Weather Rev. 139, 96-116. 699 doi:10.1175/2010MWR3392.1

700 - Mertens, J., Madsen, H., Feyen, L., Jacques, D., Feyen, J., 2004. Including prior information in the 701 estimation of effective soil parameters in unsaturated zone modelling. J. Hydrol., 294, 251-269, 702 doi:10.1016/j.jhydrol.2004.02.011. 
- Mertens, J., Madsen, H., Kristensen, M., Jacques, D., Feyen, J., 2005. Sensitivity of soil parameters in 704 unsaturated zone modelling and the relation between effective, laboratory and in situ estimates, Hydrol. $705 \quad$ Process., 19, 1611-1633, doi:10.1002/hyp.5591.

- Meyer, P. D., Rockhold, M. L., Wee, G. W., 1997. Uncertainty analyses of infiltration and subsurface 707 flow and transport for SDMP sites. Division of Regulatory Applications Office of Nuclear Regulatory 708 Research, U.S. Nuclear Regulatory Commission, Washington, USA.

- Moore, C., Doherty, J., 2005. Role of the calibration process in reducing model predictive error. Water $710 \quad$ Resour. Res. 41, W05020. doi:10.1029/2004WR003501

711 - Nghi, V. V., Dung, D. D., Lam, D. T., 2008. Potential evapotranspiration estimation and its effect on 712 hydrological model response at the Nong Son Basin, VNU Journal of Science, Earth Sciences, 24, $213-$ 713223.

714 - Olesen, J.E., Berntsen, J., Hansen, E.M., Petersen, B.M., Petersen, J., 2002. Crop nitrogen demand and 715 canopy area expansion in winter wheat during vegetative growth. Eur. J. Agron. 16, 279-294. 716 doi:10.1016/S1161-0301(01)00134-4

- Olesen, J.E., Hansen, P.K., Berntsen, J., Christensen, S., 2004. Simulation of above-ground suppression 718 of competing species and competition tolerance in winter wheat varieties. Field Crop. Res. 89, 263-280. 719 doi:10.1016/j.fcr.2004.02.005

- Overgaard, J., 2005. Energy-based land-surface modelling: new opportunities in integrated hydrological 721 modeling, Ph.D. Thesis, Institute of Environment and Resources, DTU, Technical University of 722 Denmark.

- Perry, D. A., 1994. Forest Ecosystems. The Johns Hopkins University Press, Maryland. 1. Ed. ISBN 0$724 \quad 8018-4760-5$.

- Pollacco, J.A.P., Mohanty, B.P., Efstratiadis, A., 2013. Weighted objective function selector algorithm for parameter estimation of SVAT models with remote sensing data: Parameter Estimation for Svat Model. Water Resour. Res. 49, 6959-6978. doi:10.1002/wrcr.20554 
- Pokorný, R., Tomášková, I., Havránková, K., 2008. Temporal variation and efficiency of leaf area index in young mountain Norway spruce stand. Eur. J. For. Res. 127, 359-367. doi:10.1007/s10342-008-0212-

$730 \quad \mathrm{z}$

- Rautiainen, M., Heiskanen, J., Korhonen, L., 2012. Seasonal changes in canopy leaf area index and MODIS vegetation products for a boreal forest site in central Finland, Boreal Environ. Res., 17, 72-84.

- Ridler, M.E., Sandholt, I., Butts, M., Lerer, S., Mougin, E., Timouk, F., Kergoat, L., Madsen, H., 2012. 734 Calibrating a soil-vegetation-atmosphere transfer model with remote sensing estimates of surface 735 temperature and soil surface moisture in a semi arid environment. J. Hydrol. 436-437, 1-12. $736 \quad$ doi:10.1016/j.jhydrol.2012.01.047

- Ringgaard, R., 2012. On variability of evapotranspiration - The role of surface type and vegetation. 738 Ph.D. Thesis, University Of Copenhagen, Department Of Geography and Geology, Denmark.

- Rosero, E., Yang, Z.-L., Wagener, T., Gulden, L.E., Yatheendradas, S., Niu, G.-Y., 2010. Quantifying doi:10.1029/2009JD012035

- Sahoo, G.B., Ray, C., De Carlo, E.H., 2006. Calibration and validation of a physically distributed

- Schelde, K., Ringgaard, R., Herbst, M., Thomsen, A., Friborg, T. and Søgaard, H., 2011. Comparing hydrological model, MIKE SHE, to predict streamflow at high frequency in a flashy mountainous Hawaii stream. J. Hydrol. 327, 94-109. doi:10.1016/j.jhydrol.2005.11.012

Evapotranspiration rates estimated from Atmospheric Flux and TDR Soil Moisture Measurements, Vadose Zone J., 10, 78-83, doi:10.2136/vzj2010.0060.

- Schulze, E.-D., Kelliher, F.M., Korner, C., Lloyd, J., Leuning, R., 1994. Relationships among maximum stomatal conductance, ecosystem surface conductance, carbon assimilation rate, and plant nitrogen nutrition: a global ecology scaling exercise. . Annu. Rev. Ecol. Syst. 629-660. doi: 10.1146/annurev.es.25.110194.003213. 
- Shrestha, P., Sulis, M., Masbou, M., Kollet, S., Simmer, C., 2014. A Scale-Consistent Terrestrial Systems

754 Modeling Platform Based on COSMO, CLM, and ParFlow. Mon. Weather Rev. 142, 3466-3483. 755 doi:10.1175/MWR-D-14-00029.1

- Shuttleworth, W.J., Wallace, J.S., 1985. Evaporation from sparse crops-an energy combination theory. Q.J.R. Meteorol. Soc. 111, 839-855. doi:10.1002/qj.49711146910

- Sonnenborg, T. O., Pang, B., Bruge, A., Christiansen, J. R., Stisen, S., Gundersen, P., 2013. Modeling of evapotranspiration and groundwater recharge from forest. TR32-HOBE symposium, Bonn, Germany.

- Stisen, S., McCabe, M.F., Refsgaard, J.C., Lerer, S., Butts, M.B., 2011a. Model parameter analysis using 761 remotely sensed pattern information in a multi-constraint framework. J. Hydrol. 409, 337-349. doi:10.1016/j.jhydrol.2011.08.030

- Stisen, S., Sonnenborg, T.O., Højberg, A.L., Troldborg, L., Refsgaard, J.C., 2011b. Evaluation of Climate Input Biases and Water Balance Issues Using a Coupled Surface-Subsurface Model. Vadose Zone J. 10, 37. doi:10.2136/vzj2010.0001

- Stisen, S., Højberg, A. L., Troldborg, L., Refsgaard, J. C., Christensen, B. B. S., Olsen, M., Henriksen, H. J., 2012. On the importance of appropriate precipitation gauge catch correction for hydrological modelling at mid to high latitudes. Hydrol. Earth Syst. Sc., 16, 4157-4176, doi:10.5194/hess-16-41572012.

- Stoy, P. C., Mauder, M., Foken, T., Marcolla, B., Boegh, E., Ibrom, A., Arain, M.A., Arneth, A., Aurela, 771 M., Bernhofer, C., others, 2013. A data-driven analysis of energy balance closure across FLUXNET 772 research sites: The role of landscape scale heterogeneity. Agric. For. Meteorol.171, 137-152.

- Styczen, M., Hansen, S., Jensen, L. S., Svendsen, H., Abrahamsen, P., Børgesen, C. D., Thirup, C., Østergaard, H. S., 2004a. Standardopstillinger til Daisy-modellen. Vejledning og baggrund. Version 1.2, april 2006. DHI Institut for Vand og Miljø, Denmark.

- Styczen, M., Hansen, S., Jensen, L. S., Svendsen, H., Abrahamsen, P., Børgesen, C. D., Thirup, C., Østergaard, H. S., 2004b. Appendix-samling, DHI Institut for Vand og Miljø, Denmark. 
- Sun, G., Noormets, A., Chen, J., McNulty, S. G., 2008. Evapotranspiration estimates from eddy covariance towers and hydrologic modeling in managed forests in Northern Wisconsin, USA, Agr. Forest. Meteorol., 148, 257-267, doi:10.1016/j.agrformet.2007.08.010.

- Sun, Y., Hou, Z., Huang, M., Tian, F., Ruby Leung, L., 2013. Inverse modeling of hydrologic parameters using surface flux and runoff observations in the Community Land Model. Hydrol. Earth. Syst. Sc. 17, 4995-5011. doi:10.5194/hess-17-4995-2013

- Thompson, J.R., Sørenson, H.R., Gavin, H., Refsgaard, A., 2004. Application of the coupled MIKE SHE/MIKE 11 modelling system to a lowland wet grassland in southeast England. J. Hydrol. 293, 151179. doi:10.1016/j.jhydrol.2004.01.017

- Topping, C., Olsen, J., 2006. Vegetation growth simulation in ALMaSS. Danish Ministry of the Environment report: Ukrudtsstriglingens effekter på dyr planter og ressourceforbrug, Appendix B, Danish Ministry of the Environment, Copenhagen, Denmark.

- Twine, T.E., Kustas, W.P., Norman, J.M., Cook, D.R., Houser, Pr., Meyers, T.P., Prueger, J.H., Starks, P.J., Wesely, M.L., 2000. Correcting eddy-covariance flux underestimates over a grassland. Agric. For. Meteorol. 103, 279-300.

- van Genuchten, M. Th., 1980. A closed-form equation for predicting the hydraulic conductivity of unsaturated soils, Soil Sci. Soc. Am. J., 44, 892-898. doi:10.2136/sssaj1980.03615995004400050002x.

- Van der Keur, P., Hansen, S., Schelde, K., Thomsen, A., 2001. Modification of DAISY SVAT model for potential use of remotely sensed data. Agric. For. Meteorol. 106, 215-231.

- Wang, Q., Tenhunen, J., Falge, E., Bernhofer, C.H., Granier, A., Vesala, T., 2004. Simulation and scaling of temporal variation in gross primary production for coniferous and deciduous temperate forests. Glob. Change Biol.10, 37-51. doi:10.1046/j.1529-8817.2003.00716.x.

- Wilson, K., Goldstein, A., Falge, E., Aubinet, M., Baldocchi, D., Berbigier, P., Bernhofer, C., Ceulemans, R., Dolman, H., Field, C., others, 2002. Energy balance closure at FLUXNET sites. Agric. For. Meteorol. $113,223-243$. 
- Wösten, J. H. M., Lilly, A., Nemes, A., Le Bas, C., 1999. Development and use of a database of 804 hydraulic properties of European soils, Geoderma, 90,169-185, doi:10.1016/S0016-7061(98)00132-3.

805 - Xevi, E., Christiaens, K., Espino, A., Sewnandan, W., Mallants, D., Sørensen, H., Feyen, J., 1997. 806 Calibration, validation and sensitivity analysis of the MIKE-SHE model using the Neuenkirchen 807 catchment as case study. Water Resour. Manag.11, 219-242.

808 - Zhou, M.C., Ishidaira, H., Hapuarachchi, H.P., Magome, J., Kiem, A.S., Takeuchi, K., 2006. Estimating 809 potential evapotranspiration using Shuttleworth-Wallace model and NOAA-AVHRR NDVI data to feed 810 a distributed hydrological model over the Mekong River basin. J. Hydrol. 327, 151-173. $811 \quad$ doi:10.1016/j.jhydrol.2005.11.013

812 - Zweifel, R., Böhm, J.P., Häsler, R., 2002. Midday stomatal closure in Norway spruce-reactions in the 813 upper and lower crown. Tree Physiol 22, 1125-1136. 

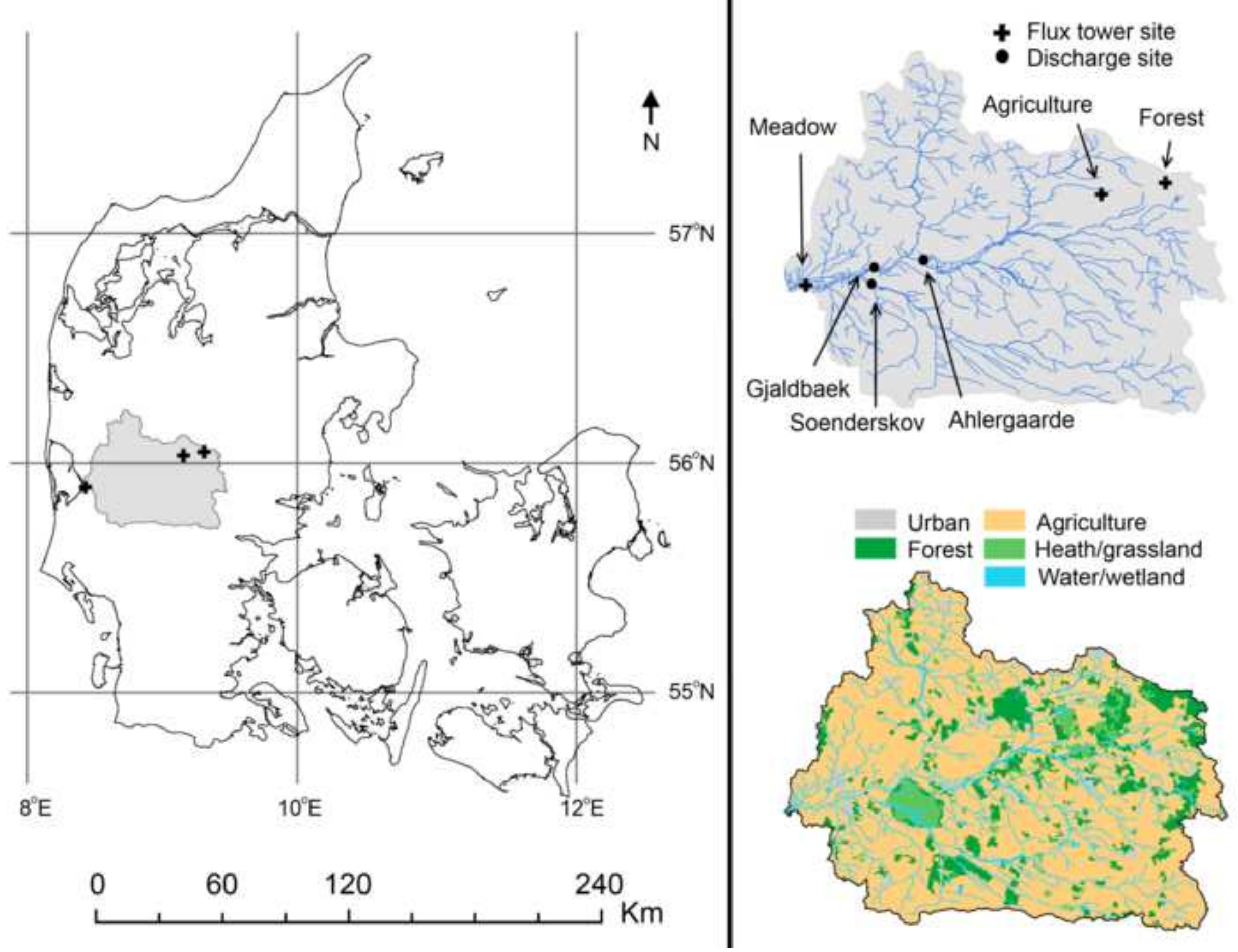

Gjaldbaek

Soenderskov Ahlergaarde 


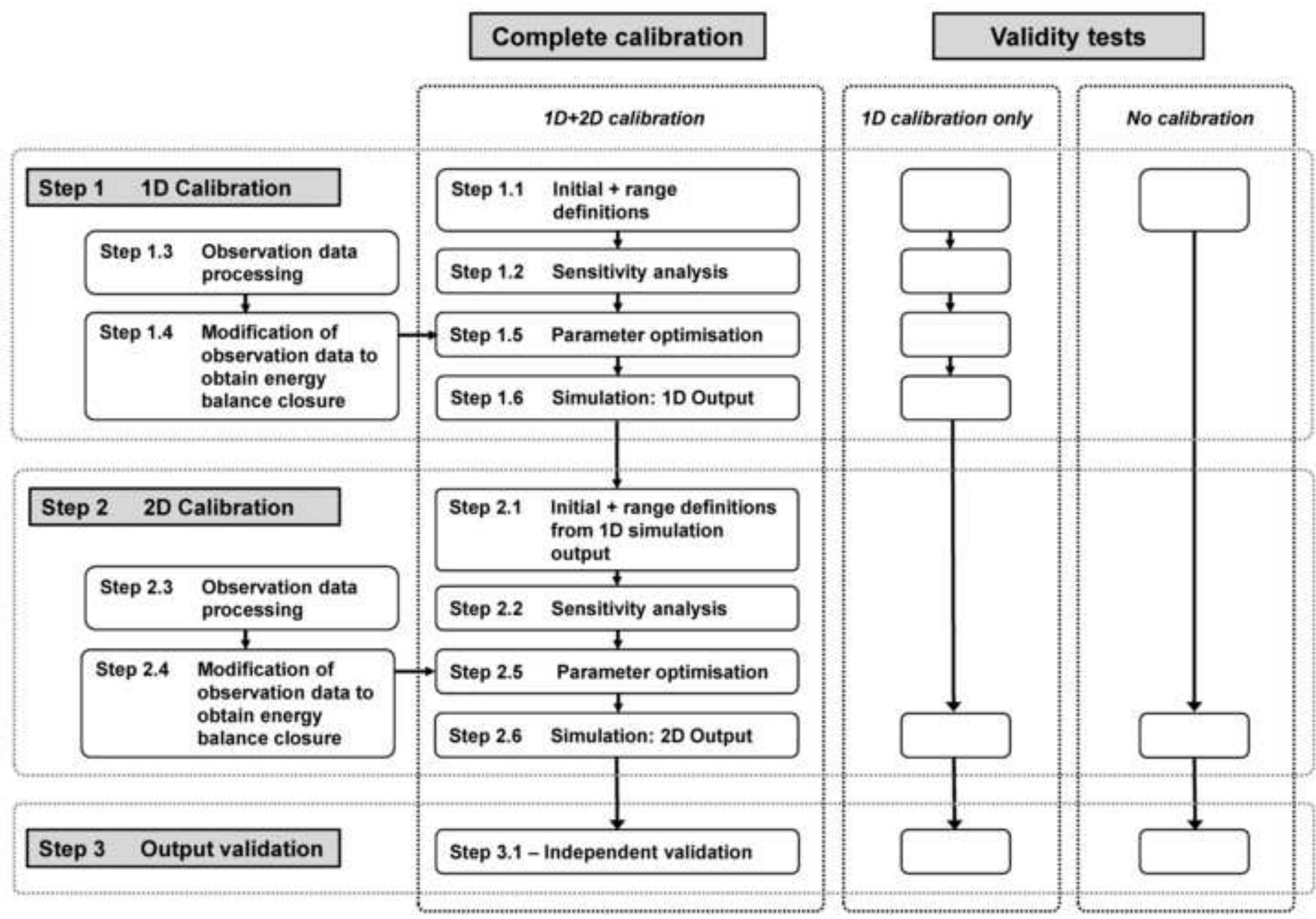




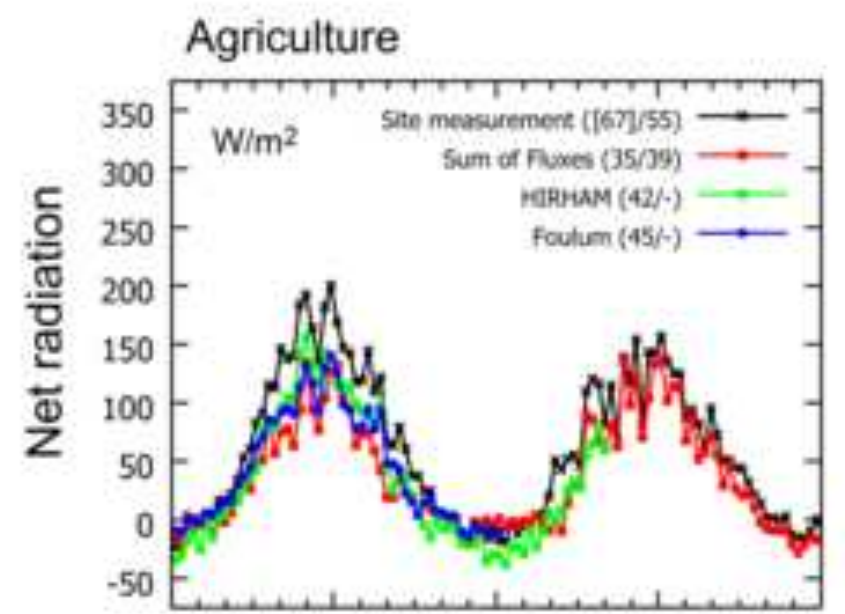

\section{Forest}
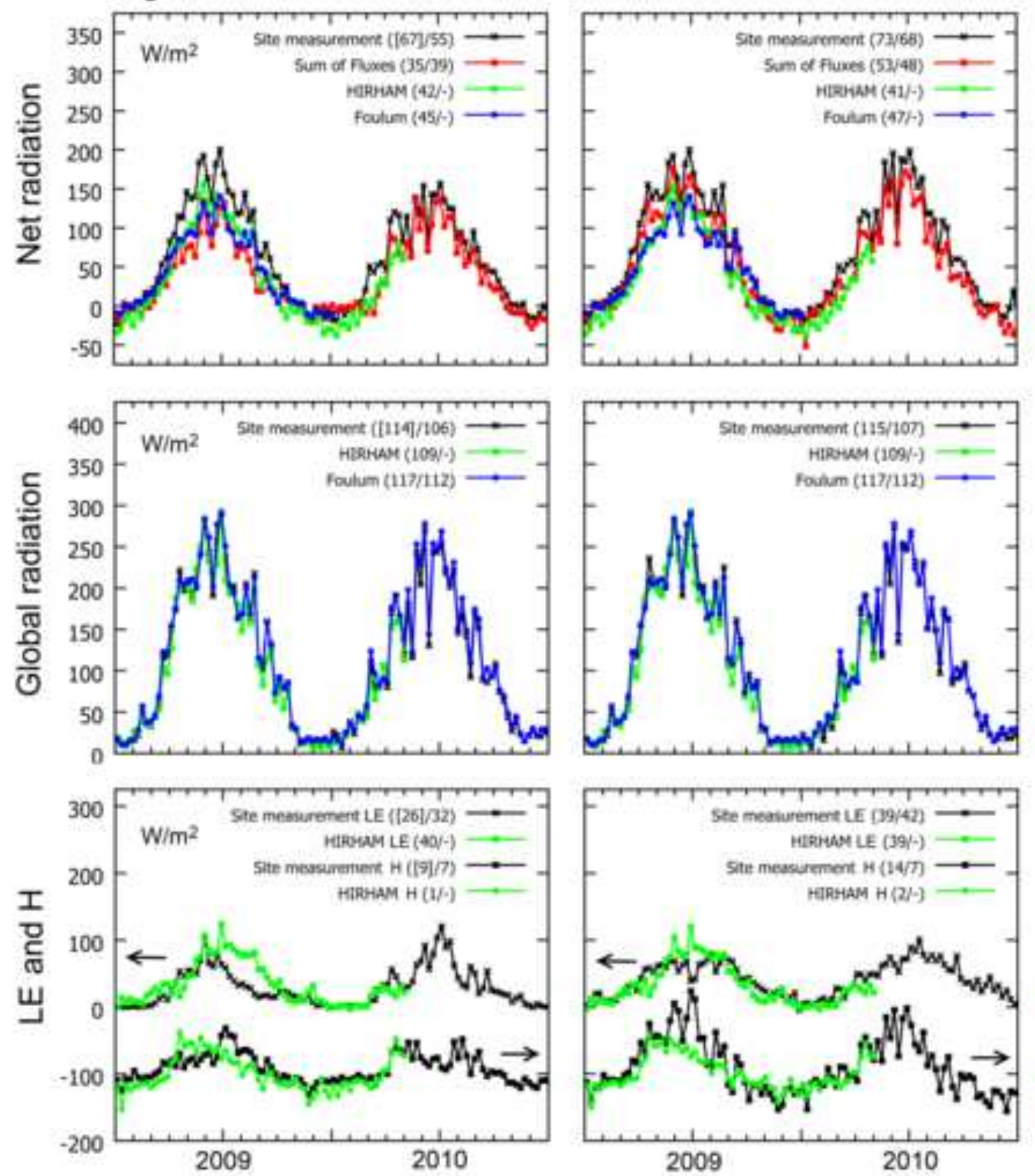
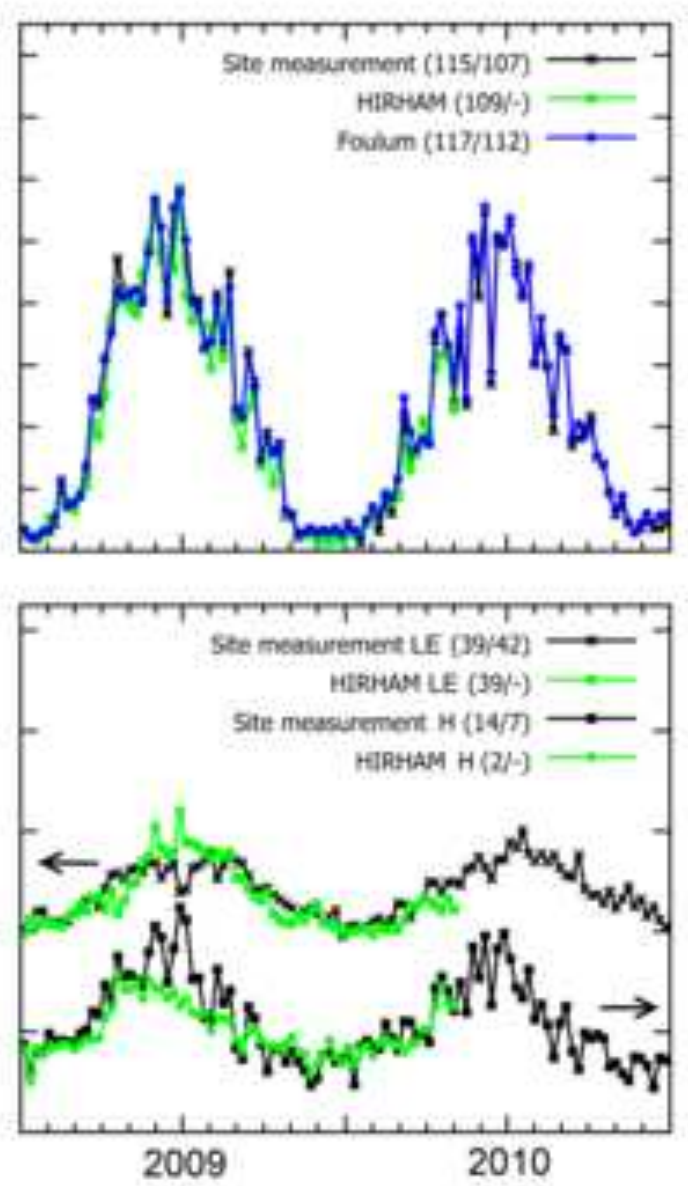
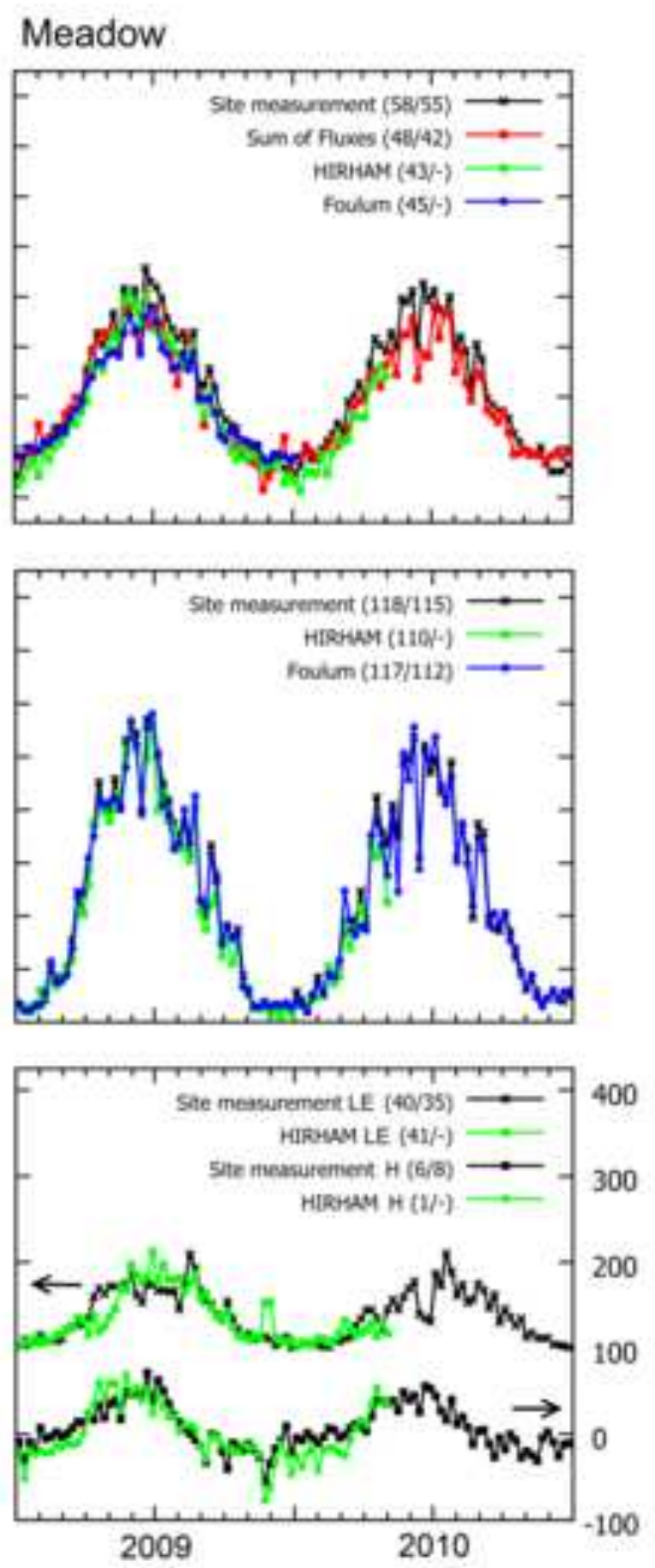

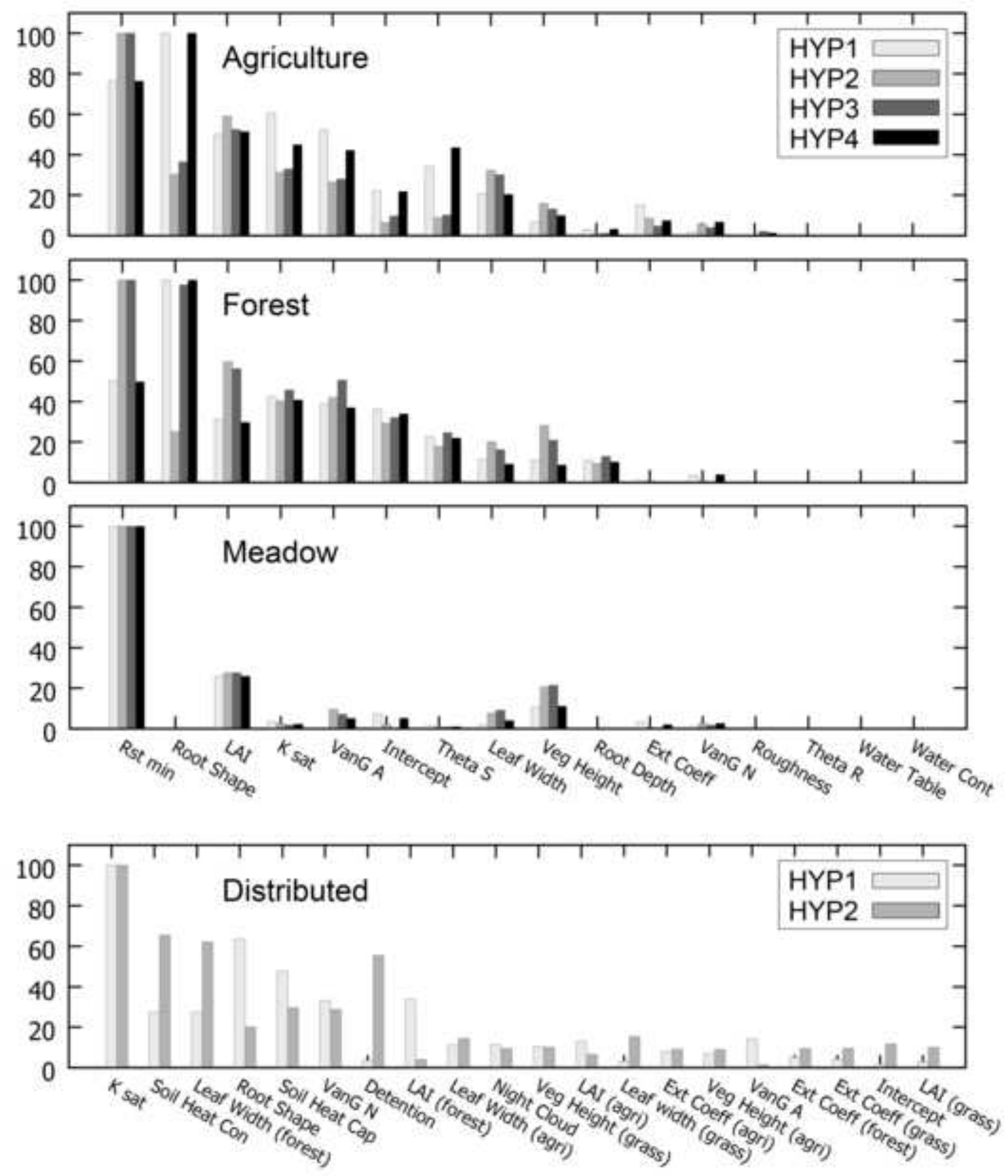

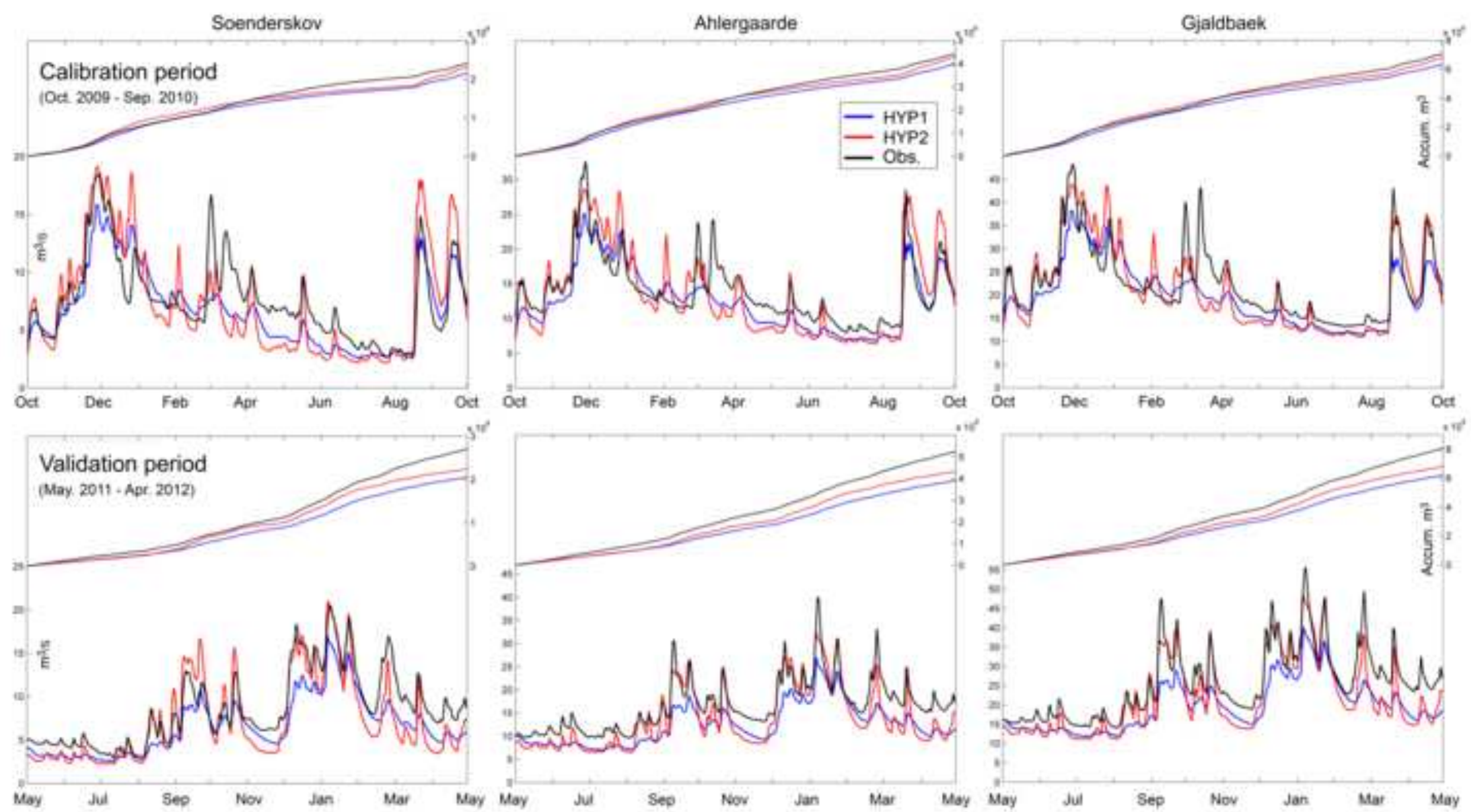


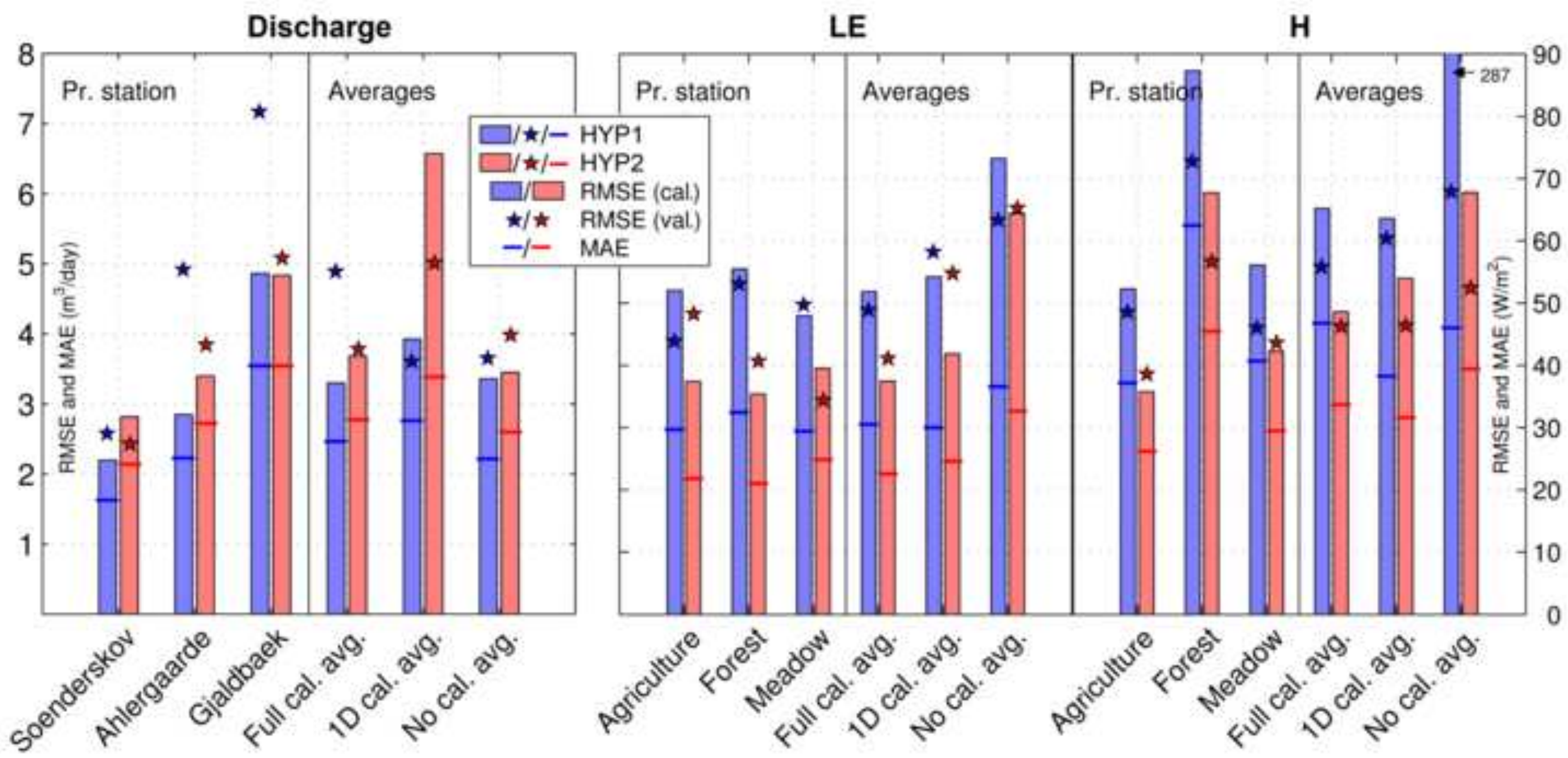



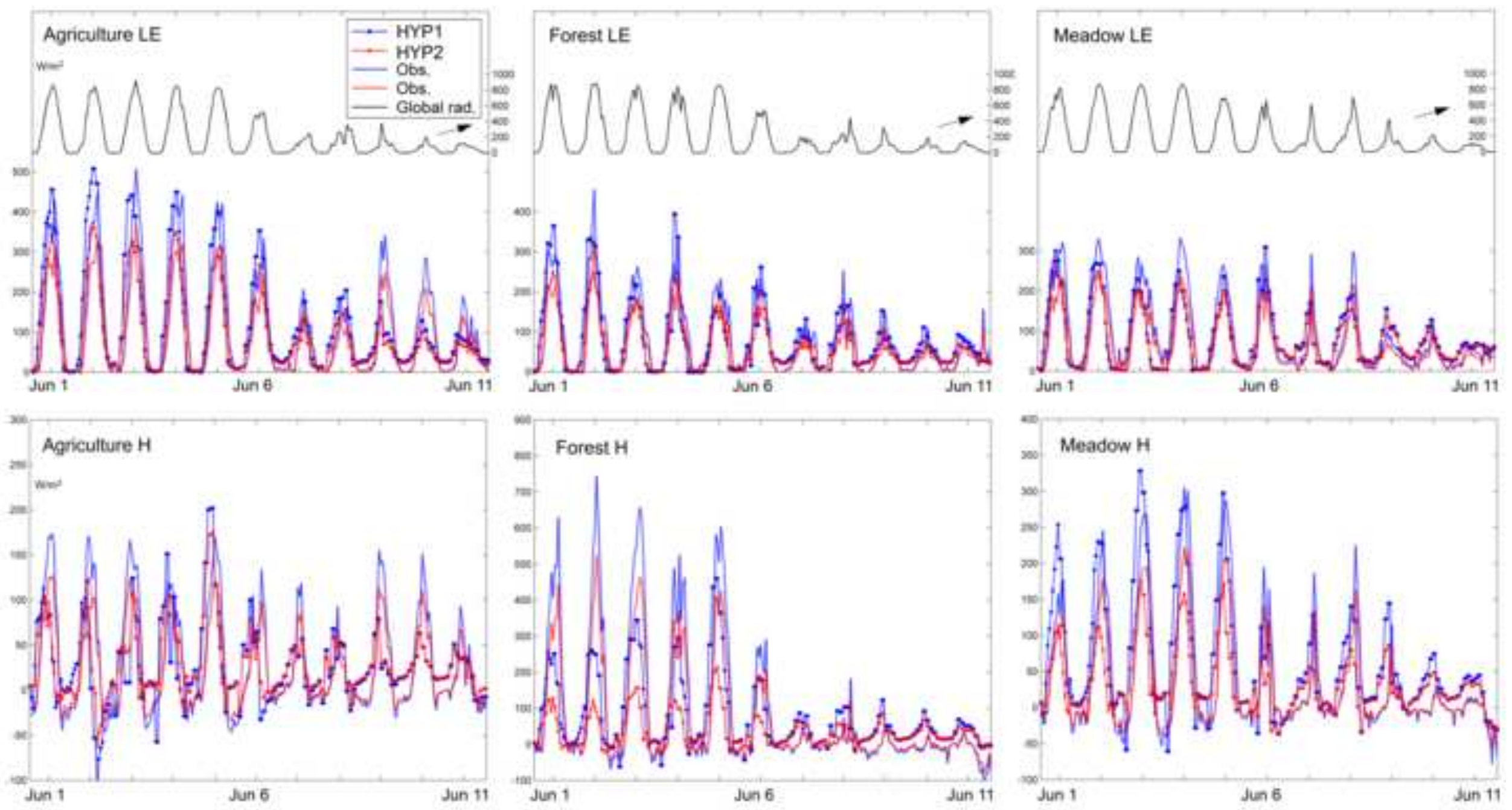

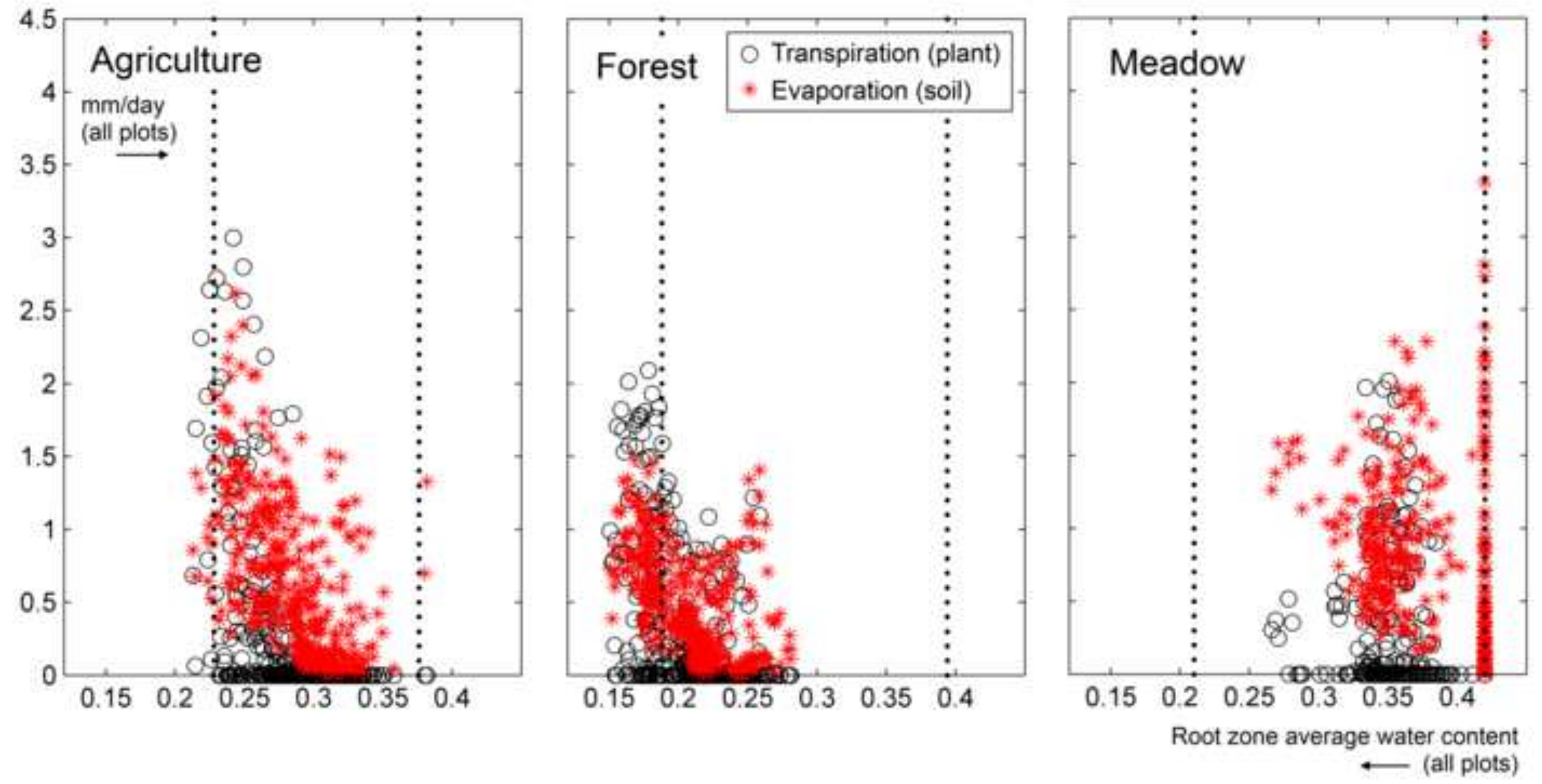